This paper reports an experimental study into the combustion of alternative gases in the form of a mixture of propane-butane with air and carbon dioxide after a stabilizing flat module whose both sides are flown around with an airflow. The ballasted fuel was fed by jets into the airflow from the holes located on the side walls of the stabilizer. In this case, the fuel and air were partially premixed. It was established that when ballasting fuel with inert admixtures, the length of the torch and the maximum temperature gradually decreased while nitrogen oxide emissions decreased. With an increase in the content of ballast in fuel, combustion breaks. The dependence of torch stability on the relative consumption of ballast has been established. To stabilize the combustion, highly reactive fuel is supplied to the recirculation zone after a stabilizer from a separate collector. Ballasted fuel passes through the next torches of high-temperature fuel; the all fuel combustion process takes place. The combined scheme of mixture formation makes it possible to adjust fuel consumption in the zones and thus maintain a stable burner power. In the case of supplying all fuel to the recirculation zone after the stabilizer, a so-called "rich" detachment is possible when the torch is detached from the stabilizer. When working under such modes, highly reactive fuel is supplied from the holes on the side walls of the stabilizer, which are placed closer to its detachment edges than the holes for the supply of ballasted fuel. At the same time, the jets of ballasted fuel also pass between the torches of highly reactive fuel so there is joint combustion of all fuel

Keywords: burner device, combustion stability, ballasted fuel gas, torch length, stabilizer, ballasting, fuel gas, combustion characteristics
UDC 662.767 .2

DOI: $10.15587 / 1729-4061.2021 .242984$

\section{DETERMINING BASIC CHARACTERISTICS OF STABILIZER MICRO TORCH BURNERS FOR THE COMBUSTION OF BALLASTED FUEL GASES}

\author{
O Iga Chernousenko \\ Doctor of Technical Sciences, Professor* \\ L e o n id B u tov s y \\ Corresponding author \\ $\mathrm{PhD}$, Associate Professor* \\ E-mail: homet129@gmail.com \\ O lena Hranovska \\ $\mathrm{PhD}$, Associate Professor* \\ Oleh Moroz \\ Postgraduate Student* \\ O leksandr S t a r chenko \\ Postgraduate Student* \\ *Department of Heat Energy \\ National Technical University of Ukraine «lgor Sikorsky \\ Kyiv Polytechnic Institute» \\ Peremohy ave., 37, Kyiv, Ukraine, 03056
}

Received date 16.08.2021 Accepted date 18.10.2021 Published date 29.10.2021
How to Cite: Chernousenko, O., Butovsky, L., Hranovska, O., Moroz, O., Starchenko, O. (2021). Determining basic characteristics of stabilizer micro torch burners for the combustion of ballasted fuel gases. Eastern-European Journal of Enterprise Technologies, 5 (8 (113)), 51-00. doi: https://doi.org/10.15587/1729-4061.2021.242984

\section{Introduction}

There is a stunning increase in natural gas prices in the world. Since the level of consumption in the energy and fossil fuel industry, in particular natural gas, greatly affects the development of the national economy of industrialized countries, this event jeopardizes the economic stability of these countries. This fact strengthens interest in conducting research on the widespread use of other fuels that can substitute natural gas. These include such highly reactionary fuel as liquefied gas (propane-butane), as well as so-called alternative gas fuels of natural and artificial origin.

This state of affairs is of particular importance for those states whose national economies experience a shortage of energy carriers, first of all, natural gas. Given the high price of imported natural gas, it is relevant for them to replace the consumption of high-calorie natural gas with medium and low-calorie gas fuels of natural and artificial origin [1].
Thus, according to the U.S. Environmental Protection Agency, methane emissions in existing and closed coal mines amounted to $1,742 \mathrm{Mt}$ in the equivalent of carbon dioxide in 2020 [2].

The use of alternative fuels could reduce the consumption of costly and scarce fossil hydrogen-carbon fuels. The inclusion in the fuel balance of agricultural and industrial waste would also reduce carbon dioxide emissions into the environment.

Thus, the use of alternative gas fuels, including in the energy and industry, and the search for means for their effective combustion is very relevant and should be one of the components in the policy of rational and frugal use of renewable energy sources.

\section{Literature review and problem statement}

Paper [3] outlines the basics of biogas technologies, analyzes the properties of biomass as an energy fuel, as well as the efficiency of bioenergy fuel use. 
Alternative fuels in the vast majority are gases containing methane in different proportions, diluted with carbon dioxide, nitrogen, air, and various additives. If we consider ballast impurities inert, their presence, in fact, boils down mainly to a decrease in the proportion of methane emitting heat and an increase in the ballast mass of heat-absorbing gases. This leads to a decrease in flame temperature, narrowing of the concentration limits of fuel combustion, and a decrease in the stability of combustion in the airflow.

The kinetics of the combustion mechanism of various ballasted gases was studied in [4]. It has been shown that fundamentally the mechanisms of combustion of methane and biogas are of the same nature.

The Gas Institute of the NAS of Ukraine conducts research and implementation in industrial boilers and installations for various purposes of biogas with various compositions [5]. The scientists established a decrease in the length of the torch with an increase in the carbon dioxide content, a reduction in the rate of flame propagation, as well as a decrease in the release of nitrogen oxides. At the same time, there is a danger of flame being detached.

In the study of mixtures of natural gas and carbon dioxide (imitation of biogas) [6], it was concluded that such a mixture can imitate biogas within certain limits and has similar characteristics to it. With an increase in the content of impurities, the length of the torch is reduced, nitrogen oxide emissions are decreased, and the torch stability decreases compared to methane.

In [7], the influence of methane-air mixtures and biogas-air on the combustion characteristics of the laminar torch was investigated. The combustion rate of the mixtures was determined and conclusions were drawn that the presence of inhibitors (carbon dioxide and nitrogen) has a greater impact on reducing the normal rate of flame spread in a rich mixture.

Study [8] tackled the combustion of gases with different compositions of the mixture imitating various gases: hydrogen, carbon dioxide, and methane. It has been established that there is no universal model of turbulent combustion of gases. The most suitable is the K- $\varepsilon$ model. Experimental studies have shown that the hydrogen supplement improves combustion stability by increasing the normal flame propagation rate.

In the industry, in order to save money, the same burners are often used when combusting low-reactive fuels, designed to burn highly reactive fuels. However, differences in the properties of these gases lead to a narrowing of the possible range of combustion, the detachment of the torch, and the appearance of a significant non-combusted residue [9].

One of the approaches to intensify the process of burning low-calorie gases while shortening the torch can be pre-mixing gas with air in the mixer, as well as multi-jet gas supply to a straight or twisted airflow [10]. However, in both cases, the problem of ensuring the stability of combustion remains when the ballast content in the gas changes.

In the case of changes in the concentration of impurities, additional means are needed to stabilize the flame. Such a tool may be the use of an additional source with a high temperature - a stabilizing (regular) torch.

This technique of gas combustion with variable characteristics is proposed in [11]. In the designed burner, the supply of natural and generator gas is provided through separate channels. The formation of a mixture of gases and their mixing with air is carried out in the burner tunnel and in the furnace itself, which leads to a decrease in the intensity of the combustion process and an increase in the length of the torch.

Recently, considerable attention has been paid to the use of ballasted gases in the energy sector, in particular, regarding gas turbines.

The European Union is implementing the project "Highly efficient gas turbine using synthetic gas" [12]. The project envisages the use of modern technologies of gasification and processing of biomass for biogas production (a mixture of $40 \div 75 \%$ methane with carbon dioxide and various impurip ties) and synthetic gas (synthesis gas is a mixture of hydrogen and carbon monoxide plus various impurities).

Research [13] was carried out on the synthesis gas of the V94.2K gas turbine unit of Siemens and Ansaldo. It is indicated that in the development of burner devices of this type, it was necessary to solve the problem associated with the high rate of flame spread due to the presence of hydrogen. The upgraded SGTS-4000F turbine burner has two gas supply lines - pilot and main. Using synthesis gas as a pilot fuel can reduce natural gas losses. In the mixing area, the combustion technique is close to burning a pre-prepared mixture. Attention is paid to the possibility of "slipping" the flame into the mixing part of the burner.

In [14], a turbine with a capacity of $2.5 \mathrm{MW}$ is used for research based on natural, passing oil, and pyrolysis gas, diesel fuel. The research was carried out using RQL technology (Rich-Burn, Quick-Mix, Lean-Burn Combustor), that is, burning a rich mixture, rapid mixing, and combusting a lean mixture. It was found that when working on synthetic fuel, there is a possibility of an increase in $\mathrm{NO}_{\mathrm{x}}$, which requires additional research.

In [15], the characteristics of a gas turbine were determined when using biogas, ethanol, and synthesis gas compared to working on natural gas. The possibility of working using biofuels has been established, but an appropriate restructuring of the combustion chamber design is required.

When using spark ignition torch, tests were carried out on three types of biofuels mixed with methane [16]. It was established that the best option is a mixture of biogas with the addition of $50 \%$ methane. Under the same conditions, the highest level of efficiency and reduction of carbon monoxide and nitrogen oxides was achieved.

The studies have shown that in order to stabilize and effectively burn low-calorie gas, not only the presence of another torch is important but also a way to organize combined combustion. The gas supply scheme depends, as a rule, on the design of a given burner device and cannot be extended to burners of another design.

In the energy and industry, register burners are traditionally used to organize the combustion workflow of fuel, including low-reactive ones. The disadvantages of register burners include significant hydraulic resistance, as well as high sensitivity of combustion completeness to a change in the coefficient of excess air $(\alpha)$ [17].

Thus, the task of burning alternative gas fuels is solved by a particular manufacturer, depending on the accepted technique for organizing the workflow and the structural implementation of the burner device.

One of the possible promising areas for ensuring the effective combustion of alternative fuel gases may be the use of micro-torch fuel combustion technology in modular burners of stabilizing type. The working process in such burners involving the combustion of high-calorie gases was studied 
at the National Technical University of Ukraine "Kyiv Polytechnic Institute (NTUU “KPI”) [18, 19].

\section{The aim and objectives of the study}

The purpose of this work is to determine the main characteristics of stabilizing modular burner devices when burning ballasted gas fuels under various schemes of mixing. Achieving the goal would make it possible to devise recommendations for the choice of design parameters of the burner depending on working conditions, to expand the range of low-reactive fuels and the scope of modular burners.

To achieve the set aim, the following tasks have been solved:

- to determine the characteristics of fuel combustion after the stabilizer when supplying gas according to various schemes of mixture formation;

- to determine the effect exerted on the combustion characteristics by the addition of impurities in the form of air and carbon dioxide when pre-mixing with gas fuel;

- to develop ways to expand the range of stable combustion of the ballasted low-reactive gas by using a combined mixture formation system;

- to devise recommendations for the organization of stable burning of ballasted fuels in stabilizing burners.

\section{The study materials and methods}

Our experimental studies were carried out at an experimental bench with variable working areas, according to standard procedures using appropriate devices and equipment. The working area of the bench is shown in Fig. 1. Air from the compressor through guide area 1, throttle grid 2 is fed to transitional area 3 , and then to working area 4 . The walls of the working area are covered with refractory lining 7 and additionally cooled with water, which is fed through nozzle 9 to cooling channel 8 , and exits through nozzle 10 . To take measurements of the temperature of gases in the furnace space and sampling for chemical analysis, fitting system 6 is provided.

The bench hosts a system of flat collectors-stabilizers 5 , through which fuel (gas) is supplied for combustion.

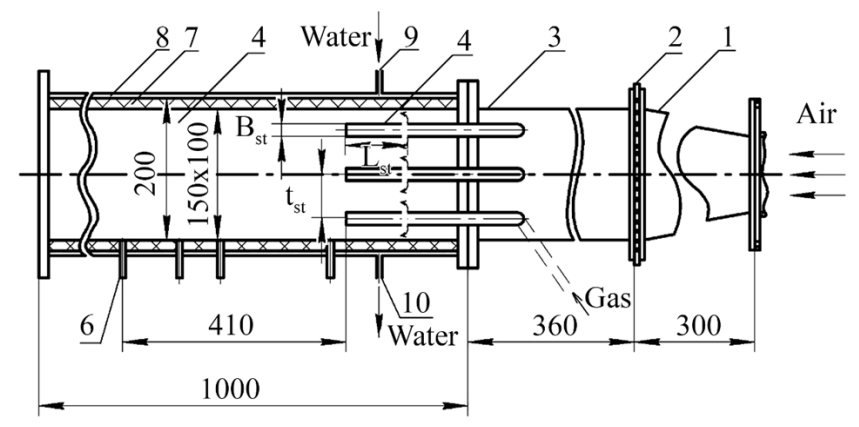

Fig. 1. Experimental bench: 1 - guide section; 2 - throttle grid; 3 - transitional area; 4 - working area;

5 - collector-stabilizer; 6 - fitting; 7 - refractory lining; 8 - cooling channel; 9 - supply of cooling water; 10 - cooling water drainage

The design of the bench makes it possible to measure and control the temperature of gases, the field of airspeed, the concentration of gas during isothermal blow-outs, and the composition of reaction products during combustion.

We performed the experimental studies into the joint combustion of highly reactive and alternative gas fuels of various compositions at burner modules.

During the research, we tested burner devices based on flat stabilizers of relatively small size, which are installed in the airflow (Fig. 2).

In a separate module of the burner, Fig. 2, $a$, case 1 includes two separate chambers and a separate fuel supply to each of them. Nozzle 2 is used to feed fuel to chamber 3, and then, through holes 4 , it is fed into the aerodynamic trace after the stabilizer (conditionally, - gas distribution scheme I).

According to a second gas distribution scheme (conditionally, scheme II), the fuel through nozzle 5 enters a separate cavity of the stabilizer and, through holes 6 , jets feed it into the airflow flowing around the stabilizer. Fig. $2, b$ shows the arrangement of modules in the burner device.
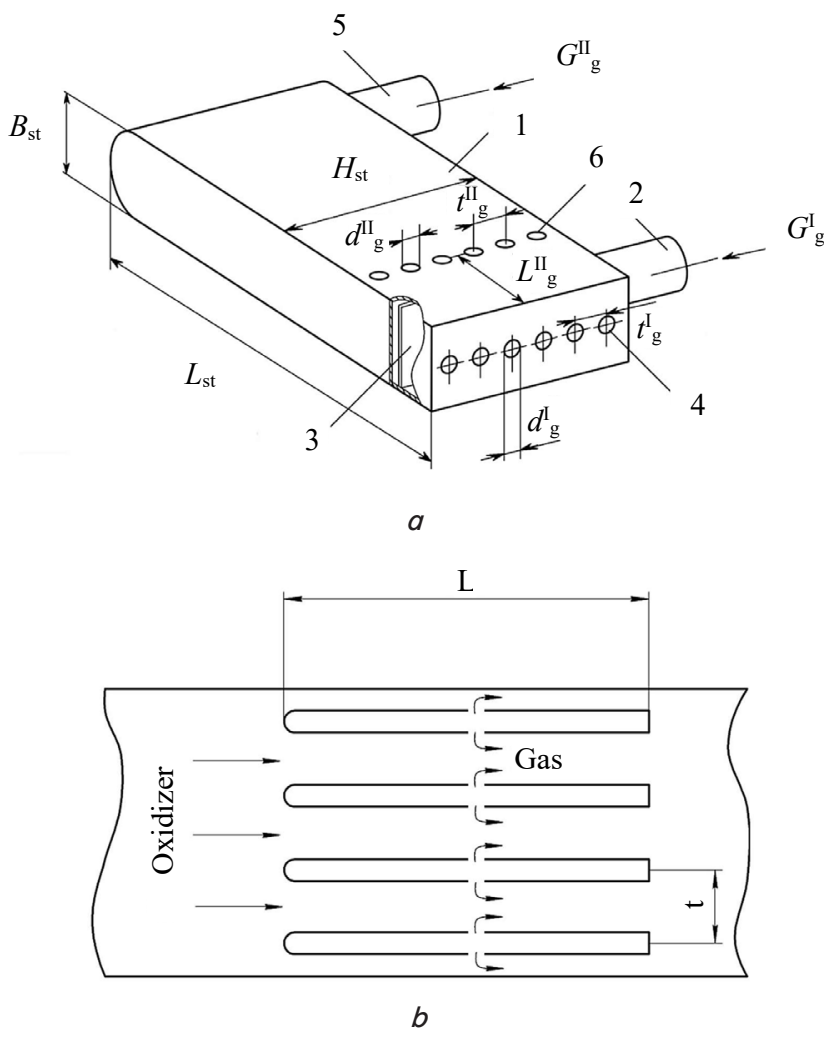

Fig. 2. Gas combustion burner: $a-$ modular stabilizer for combined gas combustion; $b$ - stabilizing micro-torch burner; 1 - case; 2, 3, 4-nozzle, chamber, and holes for gas supply to the recirculation zone (scheme I); 5, 6- nozzle and holes for gas supply to streamline airflow (scheme II)

When investigating a variant of gas supply according to scheme I, the following conditional designation of the stabilizer was adopted, for example, 15.5-0.155-8Ø3-I. The first digit means the width of the stabilizer, $B_{s t}, \mathrm{~mm}$; the second is the shading coefficient of the combustion chamber, $K_{f}=\mathrm{B}_{s t} / t_{s t}$, where $t_{s t}$ is the step of placing stabilizers; the third digit is the number and diameter of gas holes, $d_{g}, \mathrm{~mm}$; the fourth is the accepted conditional scheme of gas distribution.

When supplying gas according to scheme II, the following conditional designation was adopted, for example, 15.5-0.155-12ø2-60-I. The first digit means $\mathrm{B}_{s t}, \mathrm{~mm}$; the 
second is $K_{f}$, the third digit is the number and diameter of gas holes, $d_{g}$, mm; the fourth is the distance $L_{1}^{\mathrm{II}}$, mm, from the axis of the gas holes to the breaking edge of the stabilizer; the last figure is a conditional scheme of gas distribution.

At the trial site, tests of one or the system of modules were carried out when changing parameters in the following range: $\mathrm{B}_{s t}=15 \div 40 \mathrm{~mm}, K_{f}=0.15 \div 0.45$, the diameter of the gas holes $d_{g}=1.5 \div 3.0 \mathrm{~mm}$.

Cylinder natural gas with a methane content up to $98-99 \%$ and propane-butane cylinder mixture (50\% by $50 \%$ ) were used as high-energy fuels. Carbon dioxide $\left(\mathrm{CO}_{2}\right)$ and air were used as ballast impurities.

The designed burner device corresponds to a modern approach to the construction of burners, namely the principle of modularity and micro-torch functionality, which is implemented in the structures of burner devices and combustion chambers by world-leading manufacturers [20-24].

Each element of the burner device (in this case, the stabilizer) with the appropriate system for organizing the process of mixture formation and combustion is a separate independently working burner, in which the combustion process, especially in the initial section, occurs individually (Fig. 3).

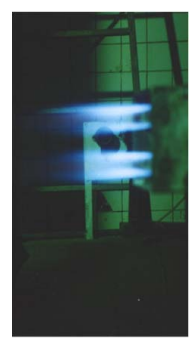

$a$

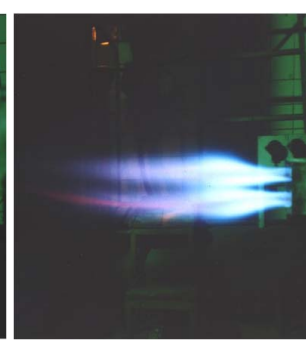

$b$

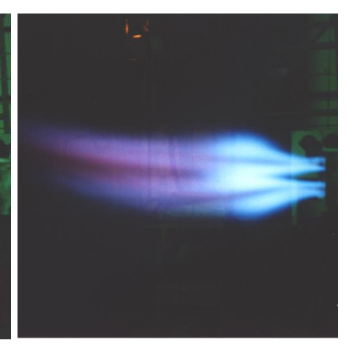

C
Fig. 3. Evolution of torch after stabilizers when changing the coefficient of excess air $\left(B_{s f}=15 \mathrm{~mm}, K_{f}=0.4\right)$ : $a-\alpha=10 ; b-\alpha=1,94 ; c-\alpha=1,01$

Our proposed approach makes it possible, in the process of designing a burner, to perform research and refinement of a separate modular element. When the burner device consists of $N$ modules, then, with the total gas consumption per burner $G_{g}$, one module accounts for $G_{g} / N$ fuel consumption. When designing a burner device for a particular facility, one can change the number of modules and, thus, the total power of the burner.

By reducing the size of the modular element, it is possible to obtain micro-torch combustion with a reduced length of the combustion zone and furnace space in general. At the same time, nitrogen oxide emissions are also reduced, the content of which depends on the time of stay of reaction products in the high temperature zone.

When implementing the proposed method of fuel combustion, characteristic features of the aerodynamic structure of the flow in the feed trail behind a poorly streamed body are used. At the same time, a recirculation flow occurs in the feed area of the stabilizer and a boundary layer is formed with an increased intensity of flow turbulence behind its breaking edge. This ensures high mass exchange characteristics of the recirculation zone, which greatly affects the stability of combustion and the nature of burnout in the trace after the stabilizer [25-27].

At the jet fuel supply according to scheme I - towards the reverse flow of the recirculation zone after the stabiliz- er, intensive mixing of fuel with high-temperature gases of this zone occurs, the fuel dissipates and a mixture is formed, which in its composition approaches the homogeneous. At the same time, the intensity of mass exchange in the recirculation zone is not enough to form a completely homogeneous mixture. In addition, only part of the oxidizer enters the recirculation zone from the boundary layer of air flowing around the stabilizer.

Thus, the process of gas combustion according to scheme I has features that are inherent in the diffusion torch, that is, the possibility of stable operation of the burner under the ignition and "poor" detachment modes at the total coefficient of excess air in the furnace space $\alpha>>1$. The diffusion torch is characterized by a wide range of work with high combustion efficiency, as well as an increase in the length of the torch with an increase in the flow rate (speed of gas jets) of fuel.

With a gradual increase in fuel consumption, the longrange of gas jets increases, the bulk of the fuel ceases to dissipate in the recirculation zone and enters a direct flow outside the zone of reverse jets. As a result, the combustion process occurs in the accompanying airflow outside the zone, which can lead to a so-called "rich" detachment and limit the possibility of using such a scheme at $\alpha \rightarrow 1.0$.

If necessary, operation with a reduced torch length under modes at $\alpha \rightarrow 1.0$ with the preservation of high intensity of the combustion process should apply fuel supply according to scheme II.

When working according to this scheme, partial preliminary mixing of gas with air occurs, and a mixture with a higher degree of homogeneity enters the combustion section of the initial edge of the stabilizer than when supplying fuel according to the scheme I. The degree of pre-mixing of air and gas supplied according to scheme II depends on the longrange gas jets in the airflow and distance $L_{1}^{\mathrm{II}}$ (Fig. 2, $a$ ) from the breaking edge of the stabilizer to the gas holes. In the case of significant movement of gas holes from the breaking edge of the stabilizer towards the airflow (an increase in $L_{1}^{\mathrm{II}}$ ) in the combustion zone, an almost homogeneous mixture of gas and air can enter the combustion zone. Gas supply according to scheme II makes it possible to provide intensive combustion and reduce the length of the torch at $\alpha^{\mathrm{II}} \rightarrow 1.0$. Due to the fact that when supplying gas according to a second scheme, the mixture of gas with air approaches the homogeneous, the torch stability under the ignition and "poor" detachment modes decreases. At the same time, one should note that when working on partial loads in the burner, there may be a decrease in the completeness of fuel combustion and the appearance of underburning.

Thus, in the stabilizing burner devices with micro-torch fuel combustion, there is a high level of fuel combustion efficiency in a wide range of changes in power and excess air coefficient. Such devices are characterized by easy and reliable launch at reduced fuel consumption, reliability, and ease of power adjustment with reduced emission of toxic nitrogen and carbon oxides.

Modular burner stabilizers of various designs and power have been widely used in the national economy of this country when burning gaseous fuel [19,28].

To ensure a stable and highly efficient operation of the burner device when changing modes in a wide range of modes, it is possible to simultaneously supply gas according to both schemes. Gas supply under a second main scheme ensures efficient combustion of fuel at $\alpha \rightarrow 1.0$. If it is necessary to expand the range of stable operation with increased 
coefficients of excess air $\alpha>>1.0$, the gas supply is enabled according to a first scheme.

\section{Results of studying the characteristics of a burner device in the combustion of ballasted gas fuels}

\section{1. Characteristics of combustion when supplying gas} according to the scheme $I$ - in a streamlined airflow

Figure $4 a-h$ shows the photographs of torches after the stabilizer $\left(\mathrm{B}_{s t}=15.5 \mathrm{~mm}\right)$ at the same air excess coefficients for two gas supply schemes: I - stabilizer 15.5-0.4-8Ø3-I when supplying gas to the recirculation zone (modes $a, c, e, g$ ); II - stabilizer 15.5-0.4-32ØI.5-85-II with the supply of gas by immersing in a streamlined airflow (modes $b, d, f, h$ ). Under gas supply scheme II, the distance from the breaking edge of the stabilizer towards the airflow was $L_{1}=85 \mathrm{~mm}$.

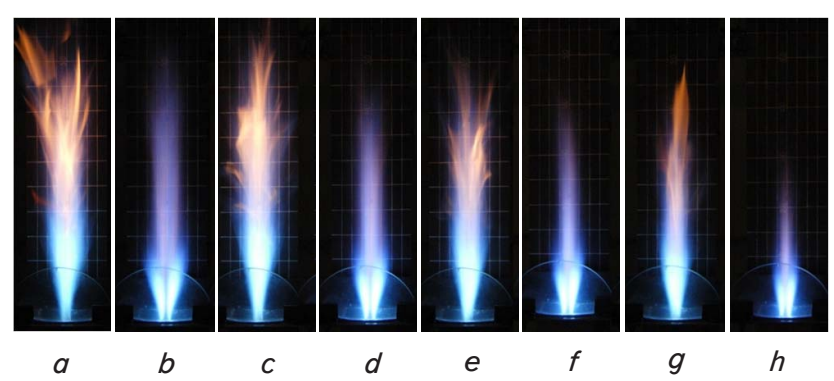

Fig. 4. Characteristics of the torch after the stabilizer in two gas supply schemes: $a-h$-comparative photographs of torches; $a, b-\alpha=5,53 ; c, d-\alpha=6,78 ; e, f-\alpha=7,73 ; g$, $h-\alpha=8,9 ; a, c, e, g-$ gas supply to the recirculation zone according to scheme I (15.5-0.155-9ø3-I); $b, d, f, h-$ gas supply by the introduction of air into the streamline airflow according to scheme II (15.5-0.155-32Ø1.5-85-II)

Fig. $4 a-h$ demonstrates that gas supply for partial pre-mixing with air makes it possible, if necessary, to reduce the length of the torch.

Fig. 5 shows the visual length of the torch for three stabilizer options.

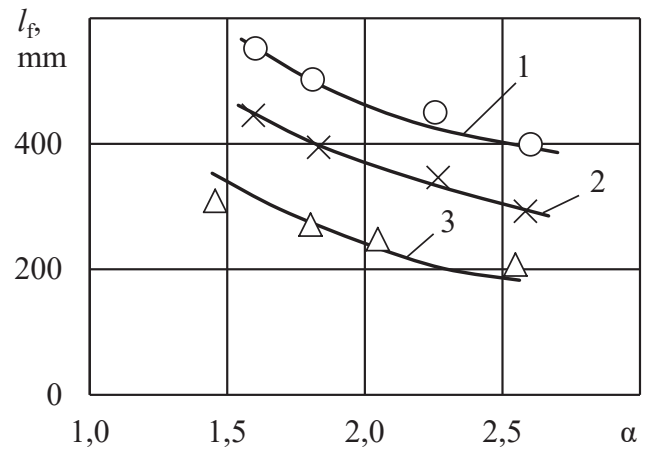

Fig. 5. Visual length of the torch after the stabilizer when supplying gas according to various schemes:

1 - supply to the recirculation zone,

stabilizer 15.5-0.4-9Ø3-I; 2, 3 - gas supply by immersion in a streamline flow, 2 - stabilizer 15.5-0.4-32Ø1.5-85-II $\left(\mathrm{L}_{1}^{\mathrm{II}}=85 \mathrm{~mm}\right) 3-15.5-0.4-32 \varnothing 1.5-120-\mathrm{II}\left(\mathrm{L}_{1}^{\mathrm{II}}=120 \mathrm{~mm}\right)$

The comparison of lines 1 and 2 shows that the supply of gas for pre-mixing with air makes it possible to reduce the torch length. Further reduction of the torch length can be achieved by increasing the distance from the gas holes to the breaking edge of the stabilizer from $\mathrm{L}_{1}^{\mathrm{II}}=85 \mathrm{~mm}$ (curve 2) to $\mathrm{L}_{1}^{\mathrm{II}}=120 \mathrm{~mm}$ (curve 3). With an increase in the distance $\mathrm{L}_{1}^{\mathrm{II}}$, more uniform mixing of gas and air occurs.

Comparative data on the effect of the mixing scheme on fuel combustion in the trace after the stabilizer in terms of $\bar{X}=X / B_{s t}$ length are shown in Fig. 6 , where $q_{3}$ is a chemical underburning, and is the relative length of the combustion zone, $X$ is the absolute length. Curve 1 was obtained through calculation according to the literary data [29] when combusting pre-mixed mixtures $\left(\mathrm{B}_{s t}=40 \mathrm{~mm}, K_{f}=0.40\right.$; $\alpha=2.0$ ); curve 2 is based on the data obtained during inkjet gas supply by the introduction of the oxidizer into the stream $\left(\mathrm{B}_{s t}=40 \mathrm{~mm}, K_{f}=0.40 ; \alpha=2.0\right)$; curve 3 - when supplying fuel to the recirculation zone after the stabilizer $\left(B_{s t}=40 \mathrm{~mm}, K_{f}=0.40 ; \alpha=2.0\right)$.

Thus, depending on the use of the appropriate mixing scheme, it is possible to influence the nature of fuel combustion. The burnout intensity increases and the length of the torch decreases in the following sequence - the combustion of the pre-mixed mixture, the supply of fuel by introducing into streamline airflow, the supply of gas to the recirculation zone.

The considered technology of micro-torch gas combustion after the stabilizers makes it possible, by changing the design parameters and the mixture formation system, to influence the characteristics of burnout, the length of the combustion zone and, accordingly, the required size of the furnace space.

Tests were carried out to establish the dependence of torch stability under gas distribution scheme II on the design and regime parameters of the stabilizer system when burning propane-butane.

Experimental data on the stabilizer systems were processed when changing the structural and regime data in the following range: the stabilizer width $\mathrm{B}_{s t}=15,5 \div 30,0 \mathrm{~mm}$; the shading coefficient of the stabilizer grid $K_{f}=0.15 \div 0.45$; the relative distance of the gas holes from the breaking edge of the stabilizer $\bar{L}_{1}=1.0 \div 8.0$, where $\bar{L}_{1}=L_{1} / B_{s t}$; the diameter of the gas holes $d_{g}=1,2 \div 3,2 \mathrm{~mm}$; the ratio of the output end plane of the stabilizer to the area of the gas holes $F_{s t} / F_{g}=26 \div 80$; the airflow temperature $\mathrm{T}_{0}=293 \div 393 \mathrm{~K}$.

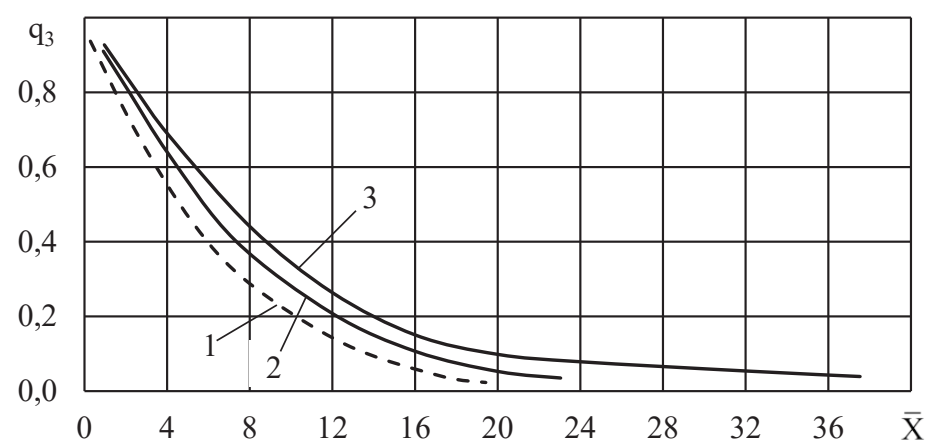

Fig. 6. Comparing the intensity of micro-torch fuel combustion after the stabilizers depending on the gas supply scheme $\left(t_{a}=200{ }^{\circ} \mathrm{C}\right.$, $\alpha=2.0)$. 1 - pre-mixing fuel with oxidizer [29] $\left(B_{s t=40} \mathrm{~mm}, K_{f=0}, 40\right)$;

2 - inkjet gas supply by the introduction of the oxidizer into a streamline flow (40-0.4-16Ø3-85-I); 3 - inkjet fuel supply to the recirculation zone (40-0.4-9Ø3-I) 
The generalized dependence of the coefficient of excess air under the mode of lean detachment $\alpha_{\max }^{I I}$ on these parameters is as follows:

$$
\alpha_{\max }^{I I}=K_{\max }^{I I} \frac{B_{s t}^{0.5}}{W_{C}^{1.2} \cdot e^{6.25 \cdot K_{f}} \cdot\left(\frac{F_{s t}}{F_{g}}\right) \cdot\left(\bar{L}_{1}^{2}+30\right)}\left(\frac{T_{0}}{273}\right)^{1.4},
$$

$K_{\max }^{I I}=0.872 \cdot 10^{5}$ is the proportionality coefficient in the case of burning propane-butane at the intensity of airflow turbulence $\varepsilon \approx 1.5 \%$.

Equation (1) shows that under scheme II of gas supply to the streamline airflow, the torch stability increases with an increase in the size of the stabilizer and air temperature. The opposite effect is observed with an increase in the airflow rate, the burner shading coefficient, the distance of the gas holes, as well as with a decrease in the relative area of the gas holes.

Fig. 7 shows the dependence of torch stability at lean detachment when supplying gas by immersion in a streamline flow on the airflow rate in the chamber for two types of stabilizers: 1 - 15.5-0.155-10Ø3-15-YI; 2 - 15.5-0.155-10Ø3-85-II, that is, respectively, at distance $\mathrm{L}_{1}=15 \mathrm{~mm}$ and $\mathrm{L}_{2}=85 \mathrm{~mm}$ from the breaking edge of the stabilizer towards the airflow.

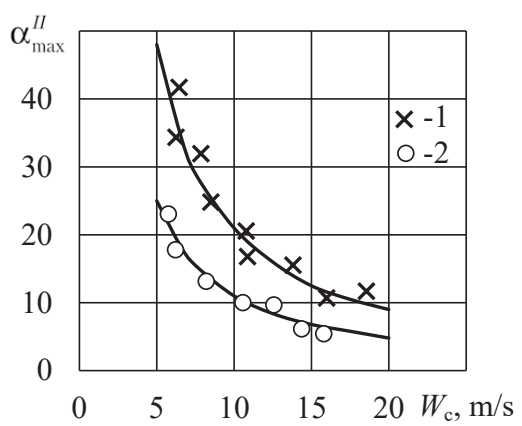

Fig. 7. Dependence of torch stability at lean detachment on airflow rate when supplying fuel to streamline airflow for two types of stabilizers: $1-15.5-0.155-1003-15-I I$; $2-15.5-0.155-10 \varnothing 3-85-$ II

Comparing curves 1 and 2 in Fig. 7 illustrates how, with other identical parameters, the torch stability decreases when the distance from the gas holes to the breaking edge of the stabilizer is increased.

For both options, the coefficient of excess air at lean detachment is $\alpha_{\max }^{I I}>2.0$, which indicates the proximity of the combustion regime to diffusion. It is also evident that when the gas holes shift towards the airflow, the stability of the torch decreases. The ultimate choice of the gas distribution system is determined by the requirements for the burner combustion stability regimes regarding lean detachment.

The results from examining one of the stabilizer options regarding the impact exerted on torch stability by ballasting the fuel gas with air and carbon dioxide under gas distribution scheme II are shown in Fig. 8.

Along the ordinate axis is the relative fuel consumption at detachment $\left(\bar{G}_{g}^{\mathrm{II}}\right)_{b a l}^{\mathrm{min}}=\left(G_{g}^{\mathrm{II}}\right)_{b a l}^{\mathrm{min}} / G_{s t}$, where $\left(G_{g}^{\mathrm{II}}\right)_{b a l}^{\mathrm{min}}$ is the fuel consumption under a lean detachment mode, $G_{s t}=F_{s t} \cdot W_{s t} \cdot \rho_{a}$ is the conditional consumption of air that flows around the stabilizer [30], $W_{s t}=W_{c} \cdot\left(1-K_{f}\right)$ is the airspeed at the output edge of the stabilizer.
Given $\left(\bar{G}_{g}^{\mathrm{II}}\right)^{\mathrm{min}}=\left(G_{g}^{\mathrm{II}}\right)^{\mathrm{min}} / G_{s t}$, the relative fuel consumption under the mode of lean torch detachment without ballast was determined. Along the abscissa axis is relative consumption of impurities, air $G_{b a l} / G_{g}^{\mathrm{II}}$, and carbon dioxide $G_{\mathrm{CO}_{2}}^{\mathrm{II}} / G_{g}^{\mathrm{II}}$.

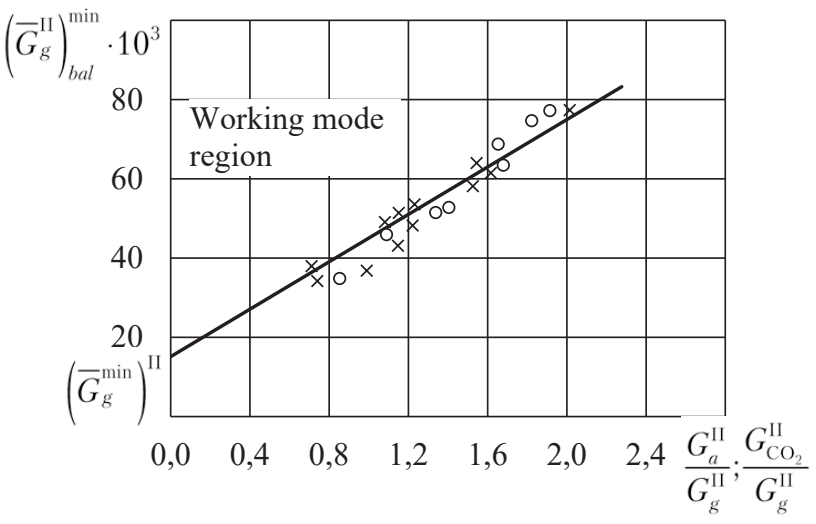

Fig. 8. Effect exerted by the supply of air and $\mathrm{CO}_{2}$ on torch stability at pre-mixing with fuel under gas distribution scheme II. Stabilizer 15.5-0.155-16Ø3-85-II. Designation of modes: $x$ - air supply; $\circ-\mathrm{CO}_{2}$ supply

The region of permissible operating modes is located in the left half of the plot from the torch detachment line. Fig. 8 shows that with increased fuel consumption, it is possible to increase the share of impurities consumption without torch detachment.

Within the accuracy of the experiment, the effect of adding ballast in the form of air and $\mathrm{CO}_{2}$ gives the same effect.

The torch stability study was carried out as follows: a certain fuel consumption $G_{g}^{\mathrm{II}}$ was set, and we gradually added the impurities, $G_{a}^{\mathrm{II}}$ or $G_{\mathrm{CO}_{2}}^{\mathrm{II}}$, to the preliminary mixing with fuel until the torch was detached.

Thus, when supplying gas according to a second scheme, there is a certain range of stable burner operation when adding ballast to fuel gas.

A value of the relative stability of the torch $\left(\bar{G}_{\mathrm{g}}^{\mathrm{II}}\right)_{\mathrm{g} a \mathrm{~m}}^{\mathrm{min}}$ during the preliminary mixing of ballast (air, $\mathrm{CO}_{2}$ ) with gas depending on the consumption of impurity $G^{\mathrm{II}}{ }_{b a l} / G_{g}^{\mathrm{II}}$ can be calculated as follows:

$$
\begin{aligned}
& \left(\bar{G}_{\mathrm{g}}^{\mathrm{II}}\right)_{b a l}^{\min }=\left(\bar{G}_{\mathrm{g}}^{\mathrm{I}}\right)^{\min }+K_{b a l}\left(\frac{G_{b a l}^{\mathrm{II}}}{G_{g}^{\mathrm{II}}}\right), \\
& \left(\bar{G}_{g}^{\mathrm{II}}\right)^{\min }=\frac{\left(G_{g}^{\mathrm{II}}\right)^{\min }}{W_{s t} \cdot F_{s t} \cdot \rho_{a}}, \\
& \left(G_{g}^{\mathrm{II}}\right)^{\min }=\frac{G_{a}^{0}}{\alpha_{\max }^{\mathrm{II}} \cdot L_{0}},
\end{aligned}
$$

where $G_{a}^{0}$ is the total air consumption in the burner, $\mathrm{kg} / \mathrm{s}$; $L_{0}$ is the mass stoichiometric coefficient, $\mathrm{kg} / \mathrm{kg} ;\left(\bar{G}_{g}^{\mathrm{II}}\right)^{\min }$ is the relative gas consumption per stabilizer at torch lean detachment without ballast; $\left(G_{g}^{\mathrm{II}}\right)^{\min }$ is the absolute gas consumption per stabilizer at torch lean detachment without ballast, $\mathrm{kg} / \mathrm{s} ; \quad K_{b a l}^{\mathrm{II}}=27.9 \cdot 10^{-3}$ is the proportionality coefficient when ballasting with air or $\mathrm{CO}_{2}$.

Observing the evolution of the torch when supplying fuel according to scheme II showed that with increased 
gas consumption, the visual length of the torch gradually increases (Fig. 9, $a-d$ ) while the temperature of gases rises (Fig. 9,d). This indicates the presence of characteristics of diffusion in the combustion process.

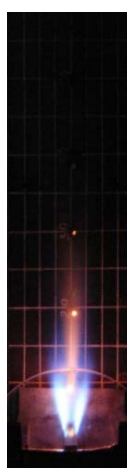

$a$

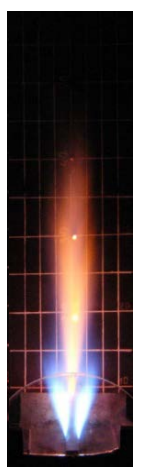

$b$

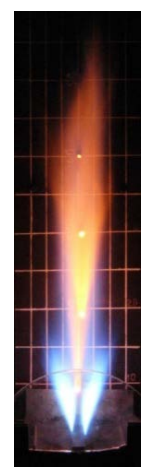

c

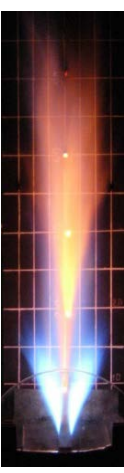

d

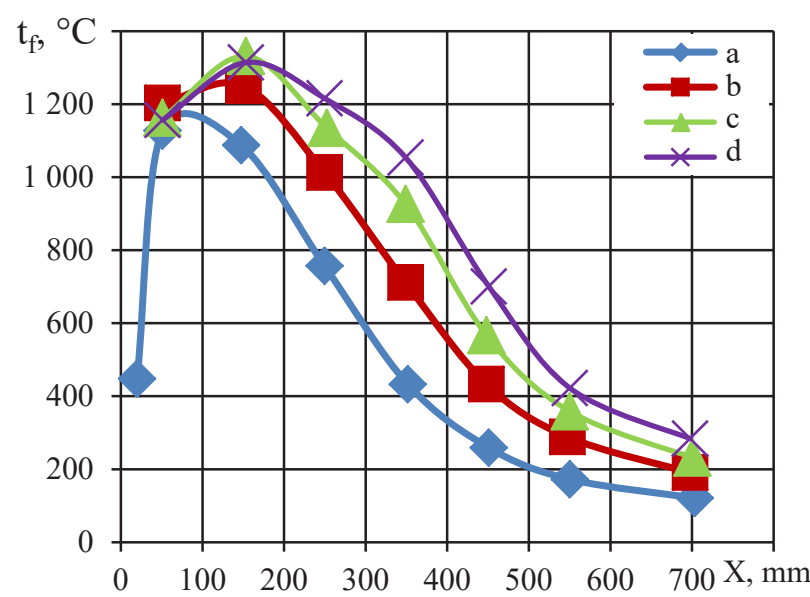

e

Fig. 9. Characteristics of fuel combustion (propane-butane) after the stabilizer with gas supply to the streamline airflow according to scheme II - 15.5-0.155-16Ø3-85-I;

$W_{c}=6.6 \mathrm{~m} / \mathrm{s} ; a-d-$ photographs of the torch; $e-$ the temperature of gases along the axis of the trace after the stabilizer; modes: $a-G_{g}^{\mathrm{II}}=0.38 \cdot 10^{-3} \mathrm{~kg} / \mathrm{s}$; $b-G_{g}^{\mathrm{II}}=0.58 \cdot 10^{-3} \mathrm{~kg} / \mathrm{s} ; c-G_{g}^{\mathrm{I}}=0.78 \cdot 10^{-3} \mathrm{~kg} / \mathrm{s}$; $d-G_{g}^{\mathrm{II}}=0.93 \cdot 10^{-3} \mathrm{~kg} / \mathrm{s}$

In Fig. 9, $e$, and the following similar figures, $X$ denotes the length of the zone of measurements of parameters at the bench, mm. Fig. 9, $e$ also shows that the most intensive combustion process is observed at the initial torch site within the recirculation zone $(3 \div 5) \cdot \mathrm{B}_{s t}$, where the main fuel share burns out, and the maximum level of gas temperature is observed.

Fig. 10 shows the torch evolution during combustion when gas is supplied according to scheme II, premixing air to the gas. In the case of working with ballasting fuel with air, the analysis of data reveals that the length of the torch gradually decreases (Fig. 10, $a-c$ ) and the temperature level of combustion products in the trace after the stabilizer decreases (Fig. 10, $d$ ).

Fig. 11 shows the evolution of the torch during combustion when gas is supplied according to scheme II and pre-mixing another ballast to the gas - carbon dioxide. In the case of working with ballasting the fuel with carbon di- oxide, the analysis of the data reveals that the length of the torch is also gradually decreasing (Fig. 11, $a-c$ ) while the temperature level of combustion products in the trace after the stabilizer decreases (Fig. 11, $d$ ).

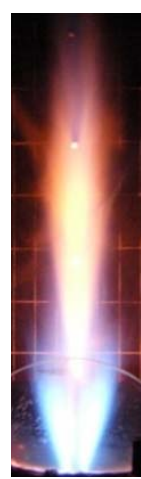

$a$

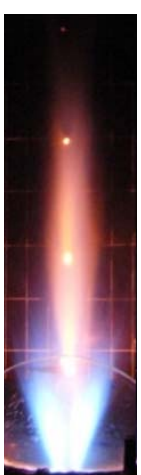

$b$

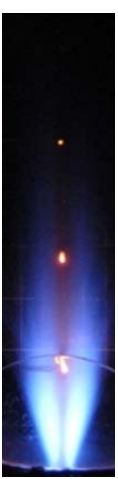

C

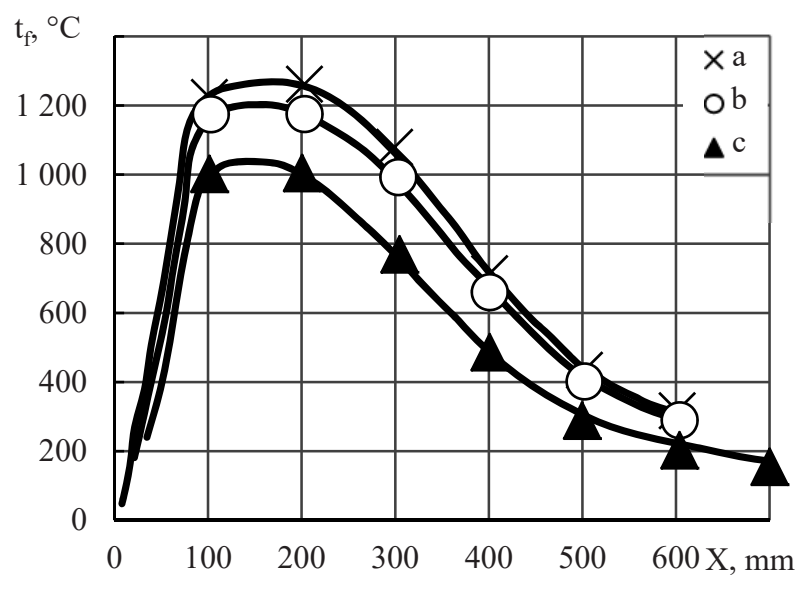

$d$

Fig. 10. Characteristics of fuel combustion after the stabilizer with the supply of gas and air mixture to the streamline airflow according to scheme II - 15.5-0.155-16Ø3-85-1 II at constant gas consumption $G_{g}^{\mathrm{II}}=0.64 \cdot 10^{-3} \mathrm{~kg} / \mathrm{s} ; W_{c}=7.0 \mathrm{~m} / \mathrm{s}$;

$a-c-$ photographs of torch; $d-$ the temperature of gases along the axis of the trace after the stabilizer; modes: $a-G_{a}^{\mathrm{II}}=0 \mathrm{~kg} / \mathrm{s} ; b-G_{a}^{\mathrm{II}}=0.25 \mathrm{~kg} / \mathrm{s} ; c-G_{a}^{\mathrm{II}}=0.50 \mathrm{~kg} / \mathrm{s}$

Fig. 12 shows a reduction in the relative length of the torch

$$
\bar{l}_{f}^{I I}=\left(l_{f}^{I I}\right)_{G_{b a l}>0} /\left(l_{f}^{I I}\right)_{G_{b a l}=0},
$$

where $\left(l_{f}^{\mathrm{II}}\right)_{G_{m}=0}$ is the length of the gas torch without ballasting; $\left(l_{f}^{\text {II }}\right)_{G_{b a}>0}{ }_{G_{b a}}=0$ is the length of the gas torch during ballasting, due to the relative consumption of impurities, air and $\mathrm{CO}_{2}$, at different values of gas consumption per stabilizer.

Fig. 12 shows that when ballasting gas with air or $\mathrm{CO}_{2}$, the length of the torch gradually decreases to the detachment.

We measured the content of reaction products at the end of the combustion zone along the torch axis with the help of the gas analyzer Testo 330 (Germany) (Fig. 13), which showed that with an increase in the consumption of gas supplied to a streamlined airflow (scheme I), the concentration of carbon monoxide $(a)$ and nitrogen oxide $(b)$ increases. 

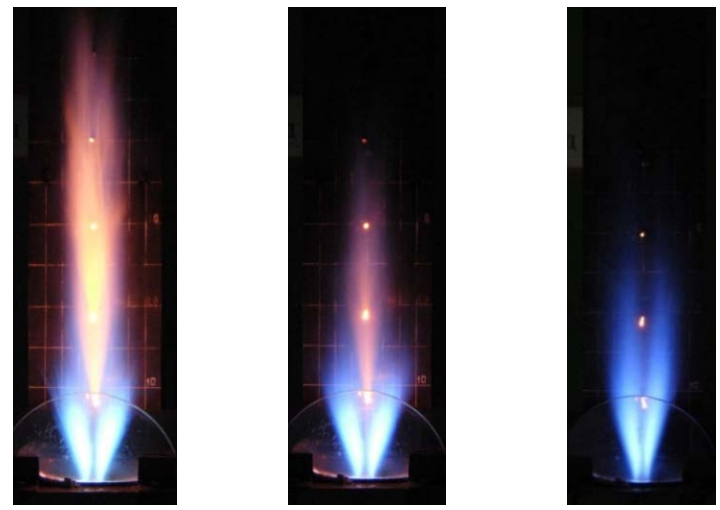

$a$

$b$

C

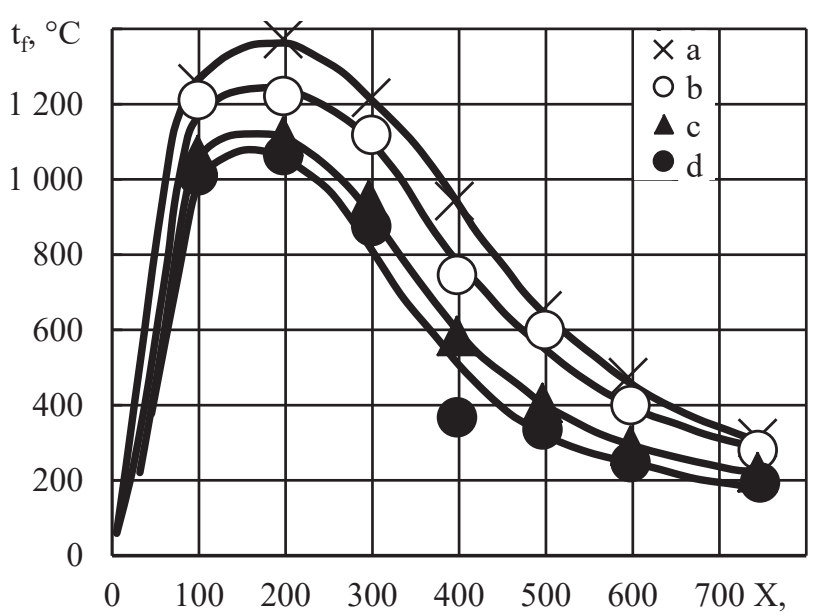

$\mathrm{mm}$

d

Fig. 11. Characteristics of fuel combustion after the stabilizer with the supply of a mixture of gas with carbon dioxide to the streamline airflow according to scheme II - 15.5-0.155-16Ø3-85-II at constant gas consumption $G_{g}^{\mathrm{II}}=1.0 \cdot 10^{-3} \mathrm{~kg} / \mathrm{s} ; W_{\mathrm{c}}=7,0 \mathrm{~m} / \mathrm{s} ; a-c-$ photographs of the torch; $d$ - the temperature of gases along the axis of the trace after the stabilizer; modes: $a-G_{\mathrm{CO}}^{\mathrm{II}}=0 \mathrm{~kg} / \mathrm{s}$; $b-G_{\mathrm{CO}_{2}}^{\mathrm{II}}=0.52 \cdot 10^{-3} \mathrm{~kg} / \mathrm{s} ; c-G_{\mathrm{CO}_{2}}^{\mathrm{II}}=0.70 \cdot 10^{-3} \mathrm{~kg} / \mathrm{s}$; $d-G_{\mathrm{CO}_{2}}^{\mathrm{II}}=1.23 \cdot 10^{-3} \mathrm{~kg} / \mathrm{s}$

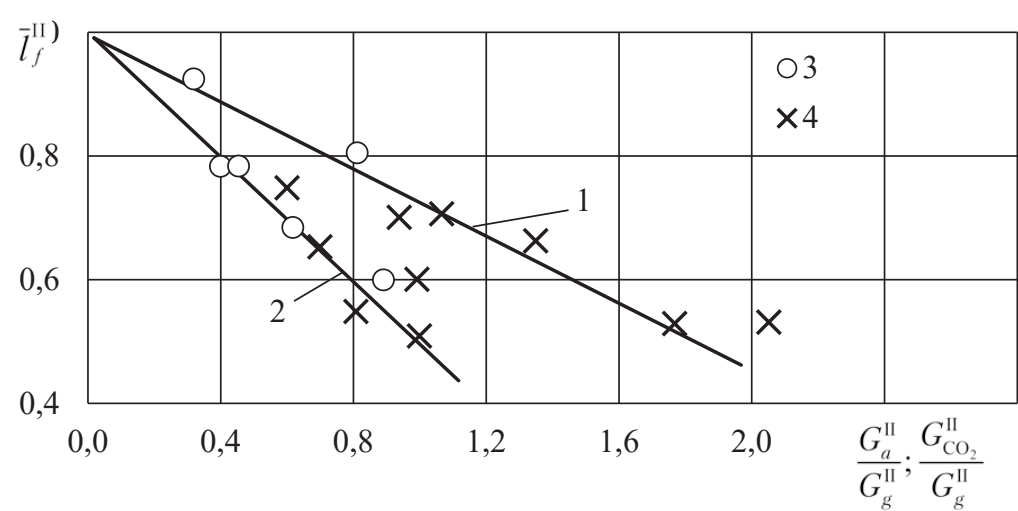

Fig. 12. Dependence of the relative length of the torch after the stabilizer when ballasting fuel with air and carbon dioxide at different impurities consumption: $1-G_{g}=(1.1 \div 1.4) \mathrm{g} / \mathrm{s} ; 2-G_{g}=(0.56-0.77) \mathrm{g} / \mathrm{s}$; 3 - ballasting with air; $4-\mathrm{CO}_{2}$ ballasting

Given that the supply of ballast impurities to the main gas is associated with a decrease in the maximum tempera- ture of gases, this leads to a decrease in the release of nitrogen oxides (Fig. 14).
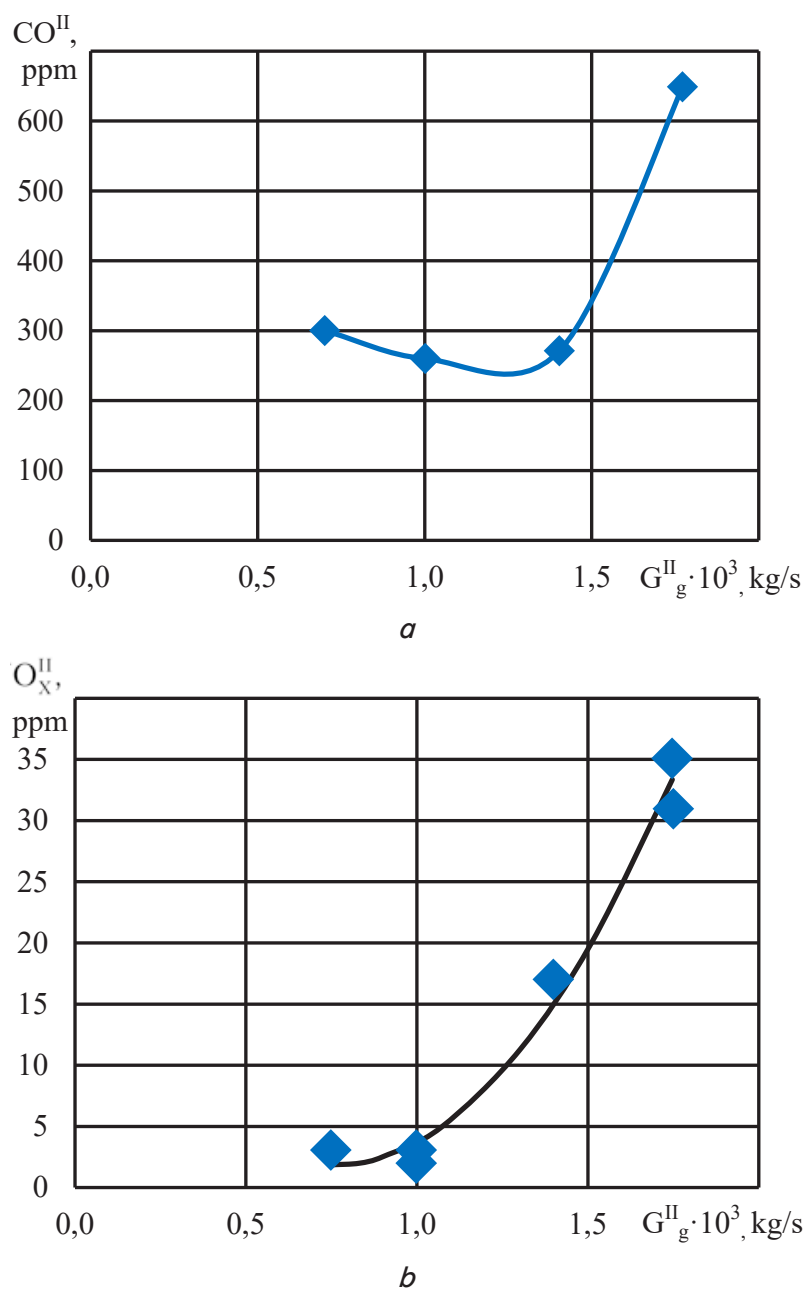

Fig. 13. The release of pollutants during the operation of the burner with the supply of fuel to a streamlined airflow (scheme II). Stabilizer 15.5-0.155-16xØ3-85-II; $W_{c}=6.8 \mathrm{~m} / \mathrm{s}$; $a-$ carbon dioxide release; $b-$ release of nitrogen oxides

The discharge of carbon oxides depends on the amount of impurity. At the first stage, there is a decrease in the content of carbon monoxide when supplying both types of impurities. Then, due to the decrease in the maximum temperature of gases in the torch, there is an increase in the concentration of underburned products (Fig. 15).

Thus, as a result of testing the stabilizer while fuel was supplied according to scheme II, in the streamline airflow, the dependence was established of lean torch detachment on the design and mode parameters, which makes it possible to influence the characteristics of torch stability. When supplying ballast in the form of air and carbon dioxide, the maximum temperature of the torch decreases, its length is reduced, and, subsequently, the flame fades. The fading of the torch is due to the fact that when the fuel is ballasted and the combustion temperature decreases, the thermal power of the recirculation zone after the stabilizer is also reduced. When the 
release of heat becomes less than the heat removal to the environment, the torch is detached.

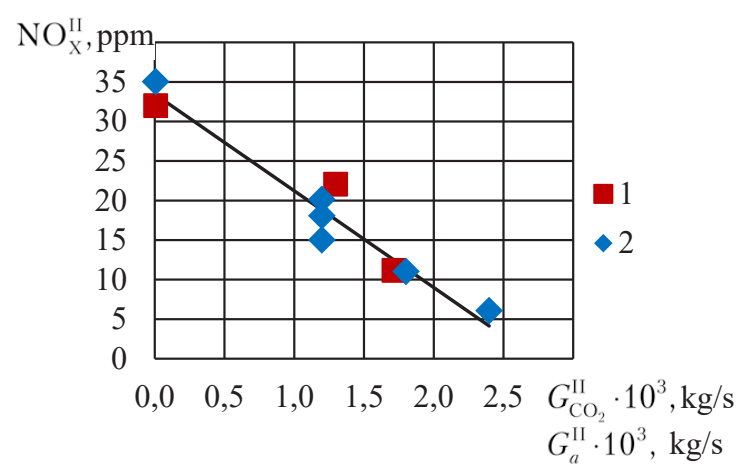

Fig. 14. Dependence of nitrogen oxides release on ballast consumption when premixing with the main gas under gas distribution scheme II: stabilizer 15.5-0.155-16xØ3.0-85-I; $W_{c}=6.8 \mathrm{~m} / \mathrm{s} ; G_{G}^{\mathrm{II}}=1.4 \cdot 10^{3} \frac{1}{2} \mathrm{~kg} / \mathrm{s} ; 1-$ carbon dioxide; 2 - air

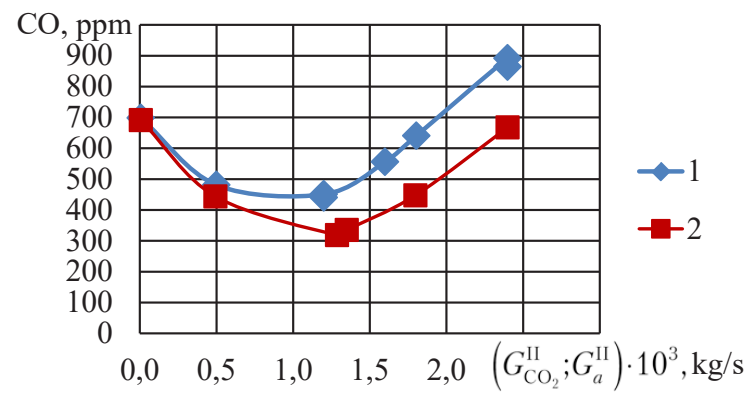

Fig. 15. Dependence of carbon monoxide release on ballast consumption when premixing with the main gas under gas distribution scheme II: stabilizer 15.5-0.155-16xØ3.0-85-I; $W_{\mathrm{C}}=6,8 \mathrm{~m} / \mathrm{s} ; G_{g}^{\mathrm{II}}=1,4 \cdot 10^{-3} \mathrm{~kg} / \mathrm{s} ; 1$ - carbon dioxide; 2 - air

5. 2. Characteristics of combustion when supplying gas according to scheme $I$ - in the recirculation zone after the stabilizer

We tested the supply of highly-reactive fuel to the recirculation zone by jets from the holes in the end wall of the stabilizer (Fig. 2, holes 4) using the following stabilizing systems: $\mathrm{B}_{s t}=15.5 \div 30 \mathrm{~mm}, K_{f}=0.155 \div 0.45, d_{g}=1.5 \div 3.0 \mathrm{~mm}$.

The mechanism of mixture formation and combustion of fuel after the stabilizer when feeding to the recirculation zone, as well as the influence of regime and design factors, were considered in [18,25-27]. Taking into consideration the main provisions from those works, as well as appropriate clarifications in the process of our research, the reported data were summarized by the following dependence:

$$
\alpha_{\max }^{I}=\frac{K_{\max }^{I} \cdot B_{s t}^{0.5} \cdot d_{g}^{0.35} \cdot\left(\frac{F_{g}}{F_{s t}}\right)^{0.2}}{W_{C} \cdot K_{f}\left(1+K_{f}\right)}
$$

where $K_{\max }^{I}=4.3$ in the case of airflow turbulence $\varepsilon \approx 1.5 \%$.

Fig. 16 shows data, for one of the stabilizer options 15.5-0.155-8Ø3-I, on the lean detachment of the torch.

When supplying gas to the recirculation zone, the degree of diffusion of the combustion process is higher than when feeding by immersing in a streamlined flow, and the stability of the torch, respectively, is higher (Fig. 6).

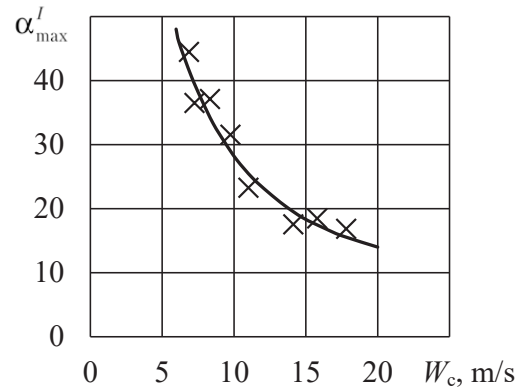

Fig. 16. Characteristics of lean detachment when supplying gas to the recirculation zone after the stabilizer 15.5-0.155-8Ø3-।

Fig. 17 shows the temperature field along the torch axis when the stabilizer is flown around by an airflow. With an increase in gas consumption, the maximum temperature rises and shifts along the torch, respectively, increasing the size of the torch.

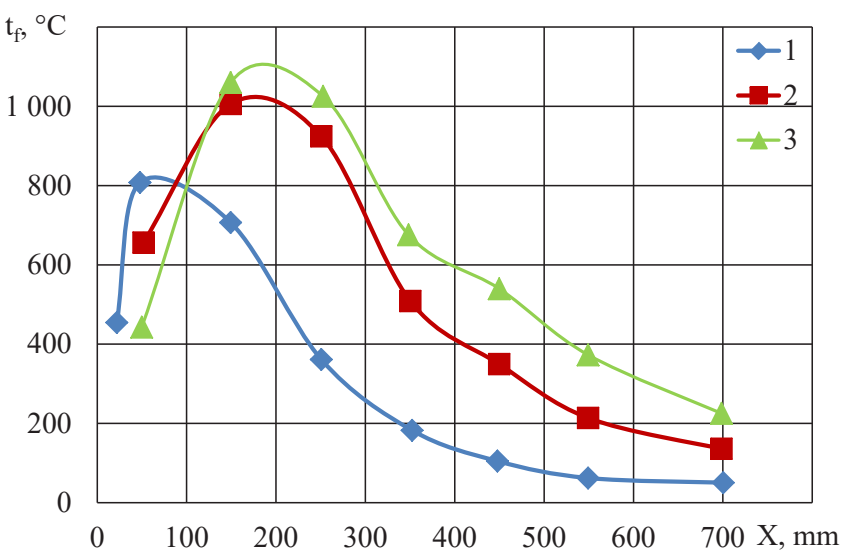

Fig. 17. Change in the temperature of gases along the torch axis when supplying propane-butane to the recirculation zone - scheme I: stabilizer 15.5-0.155-8Ø-3I; $W_{c}=6.8 \mathrm{~m} / \mathrm{s}$;

$1-G_{g}^{\mathrm{I}}=0.1 \cdot 10^{-3} \mathrm{~kg} / \mathrm{s} ; 2-G_{g}^{\mathrm{I}}=0.24 \cdot 10^{-3} \mathrm{~kg} / \mathrm{s} ;$

$$
3-G_{g}^{\mathrm{I}}=0.35 \cdot 10^{-3} \mathrm{~kg} / \mathrm{s}
$$

Fig. 17 shows that with an increase in gas consumption according to scheme I, it is possible to provide, in close proximity to the stabilizer, the temperature of gases in the recirculation zone at the level $(1,000 \div 1,100){ }^{\circ} \mathrm{C}$, which may be sufficient for reliable ignition of the ballasted fuel supplied according to scheme II, even in the case where the fuel mixture leaves the concentration limits of combustion.

5. 3. Burner operation with a combined mixture formation system - gas supply according to schemes I and II

In conducting studies with gas supply according to scheme I, it was found that with a decrease in gas consumption and, accordingly, an increase in the total coefficient of excess air in the furnace space, there was a decrease in the completeness of combustion (Fig. 18).

In such cases, it is possible to connect the gas supply according to scheme I, that is, to organize the next torch of highly reactive fuel. As a result, the combustion products of the main fuel would pass through the system of high-temperature jets of the next torch and, as it was established, the total completeness of combustion increased. 

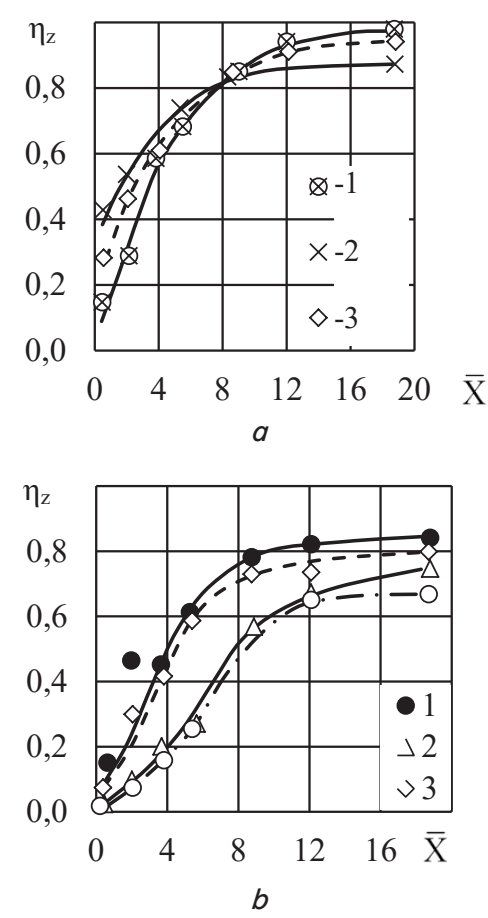

Fig. 18. Characteristics of fuel combustion in burner devices of stabilizer type with combined gas supply to the recirculation zone (scheme I) and in a streamline airflow (scheme II): $a-1$ - stabilizer 30-0.45-16Ø3-I, $\alpha=3,94$;

2 - 30-0.45-10Ø3-80-II, $\alpha^{\mathrm{II}}=4,86 ; 3-$ combined operation: $\alpha^{\mathrm{I}}=21.8, \alpha^{\mathrm{II}}=5,26, \alpha^{\Sigma}=4.25$.

$b-1-30-0.45-10 \varnothing 3-80-\mathrm{II}, \alpha^{\mathrm{II}}=1,47 ; 2-30-0.45-16 \varnothing 3-\mathrm{I}$, $\alpha^{\mathrm{I}}=1,53 ; 3-$ combined operation: $\alpha^{\mathrm{I}}=8,35, \alpha^{\mathrm{II}}=2,0, \alpha^{\Sigma}=1,61$; $4-\alpha^{\mathrm{I}}=4,6, \alpha^{\mathrm{II}}=2,0, \alpha^{\Sigma}=1,4$

Based on the data in Fig. 18, we can conclude that with the combined gas distribution, the total length of the combustion zone is determined by the total fuel consumption and fuel combustion patterns according to scheme I.

When using ballasted fuel (a mixture of propane-butane with carbon dioxide or air) and supplying the fuel according to scheme II, it was also possible to significantly increase the stability of the torch by supplying highly reactive fuel (propane-butane) according to scheme I. Gas consumption according to scheme I corresponds to the value of the excess air ratio at the boundary of lean detachment $\alpha_{0}^{I} \approx 10$. The stability of combustion of the combined torch after the stabilizer was ensured at the maximum, achieved under the conditions of the bench, air content in gas $G_{a}^{\mathrm{II}} / G_{g}^{\mathrm{II}} \approx 10$.

Fig. 19 shows the photographs of the torch; Table 1 gives the test modes of the stabilizer with combined gas and air supply. The designation of the stabilizers: according to scheme I - 15.5-0.155-8Ø3-I; according to scheme II - 15.5-0.155-16Ø3-85-II.

Table 1

Stabilizer test modes with combined gas supply according to scheme I and scheme II involving the pre-mixing with air

\begin{tabular}{|c|c|c|c|c|c|}
\hline Mode & $a$ & $b$ & $c$ & $d$ & $e$ \\
\hline$G_{g}^{\mathrm{II}} \cdot 10^{-3}, \mathrm{~kg} / \mathrm{s}$ & 1.4 & 1.4 & 1.4 & 1.4 & 1.4 \\
\hline$G_{a}^{\mathrm{II}} \cdot 10^{-3}, \mathrm{~kg} / \mathrm{s}$ & - & 0.45 & 1.1 & 1.35 & 1.35 \\
\hline$G_{g}^{\mathrm{I}} \cdot 10^{-3} \mathrm{~kg} / \mathrm{s}$ & - & - & - & - & 0.26 \\
\hline
\end{tabular}

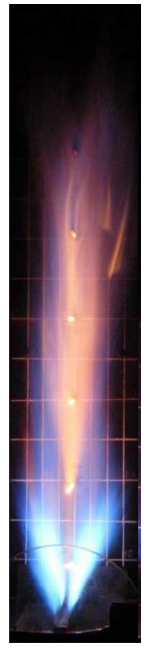

$a$

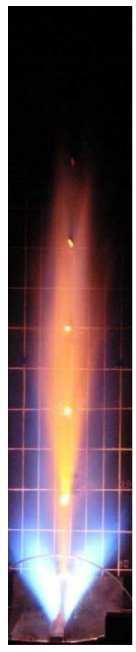

$b$

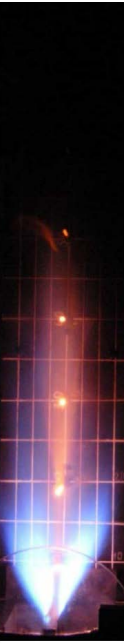

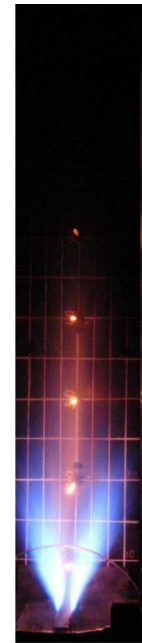

$d$

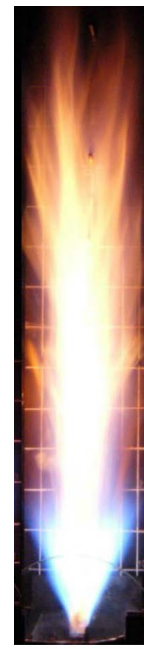

e
Fig. 19. Photographs of the torch after the stabilizer during combined operation; $W_{\mathrm{K}}=6,8 \mathrm{~m} / \mathrm{s} ; a-$ supply of the main gas according to scheme II, $b-e-$ premixing air to the main gas; $e$ - additional supply of stabilizing gas according to scheme $\mathrm{I}-$ to the recirculation zone

Studies have shown that the stability of the combustion of ballasted fuel, which is supplied according to scheme II, is determined by the stability of the combustion of the stabilizing torch of scheme I. This makes it possible to significantly expand the limits of the stable operation of the entire burner device.

Based on the study results, we can conclude that in order to ensure reliable combustion of ballasted (alternative) fuel with almost unlimited change in the concentration of impurities, it is necessary to supply this fuel according to scheme I. Another torch is formed by supplying highly reactive fuel under scheme I with a flow rate that meets the requirements for the stable combustion of this diffusion torch.

Tests were carried out to determine the effect on the combustion process exerted by ballast impurities of different concentrations and different quality compositions - from the air involved in fuel combustion to the absolutely inert additive in the form of carbon dioxide. From the study results, we can conclude that the composition of ballast impurities practically does not affect the stability of combustion if one organizes the supply of the mixture through a system of high-temperature diffusion torches.

As a result, one can formulate a general approach to designing a burner device, which is intended to burn fuels with different and time-variable compositions.

A workflow can be organized as follows:

Depending on the requirements for the characteristics of the burner device, which are due to the requirements for fuel-using equipment, the fuel supply can be organized according to scheme I - the supply of gas to the recirculation zone, or according to scheme II - immersion of gas jets into streamlining airflow. In accordance with the adopted scheme, the gas distribution system is calculated. One should consider that when supplying gas according to scheme I, effective combustion of fuel in a wide range of modes in terms of change in the coefficient of excess air is ensured, but, at the same time, there is an increased length of the combustion zone.

With a decrease in the coefficient of air excess $\alpha \rightarrow 1.0$, under this scheme, a "rich" detachment of the torch is possi- 
ble. When supplying gas according to scheme I, effective combustion is provided at $\alpha \rightarrow 1.0$, and a shorter torch. At the same time, when working under partial load modes, $\alpha>>1.0$, the appearance of underburning is likely.

If, during operation, the content of ballast impurities in alternative fuel increases, and the thermal power of the burner decreases, increasing the burner power within certain limits can be ensured by an increase in fuel consumption.

In the case of designing a burner with a wide change in the concentration of ballast impurities in the fuel, the option should be taken as a basis with the supply of alternative fuel to streamlined airflow (scheme II), and stabilizing fuel - into the recirculation zone (scheme I). With a decrease in the thermal power of the burner, and the impossibility of compensation for the power by increasing the consumption of the main alternative fuel, as well as when the mixture (fuel+impurities) leaves the concentration limits of ignition, the supply of highly reactive fuel according to scheme I is enabled. In this case, the stability of combustion in the burner is determined by the characteristic of a first scheme. It should be considered that the total length of the torch is determined by the characteristics of combustion under scheme I of gas distribution.

\section{4. Characteristics of the working process when sup-} plying gas at the level of breaking edges of the stabilizer

When the burner operates with a combined gas supply and there is an increase in the consumption of highly reactive fuel according to scheme I, the structure of the recirculation zone may be violated while the bulk of the fuel leaves the recirculation zone. This could lead to an increase in the length of the torch, the appearance of underburning with insufficient furnace space, as well as the danger of the appearance of "rich" torch detachment.

To ensure the possibility of operation of the stabilizing torch at the coefficient of excess air $\alpha \rightarrow 0$, it is necessary to eliminate the effect of gas jets on the structure of the recirculation zone.

In this case, the design of the stabilizer shown in Fig. 20 can be used. Ballasted fuel is supplied to the streamline airflow from hole 5 , which are located at distance $L_{1}^{\mathrm{II}}$ from the breaking edge of the stabilizer. Stabilizing high-reactive fuel is supplied to the streamlined airflow from hole system 4, located closer to the breaking edge of the stabilizer at distance $L_{1}^{\mathrm{I}}<L_{1}^{\mathrm{II}}$.

When supplying highly reactive fuel by immersion in a streamlined airflow, partial mixing of gas with air occurs, which leads, as can be seen from Fig. 6, to reducing the length of the torch compared to the supply of gas to the recirculation zone according to scheme I. At the same time, as can be seen from data in Fig. 7, 16, it should be borne in mind that when feeding by immersions, the limits of stable work narrow in relation to the coefficient of excess air on the lean detachment of the torch.

Photographs of the torch when supplying gas at the level of breaking edges of the stabilizer and the temperature of combustion products at different gas consumption are shown in Fig. 21.

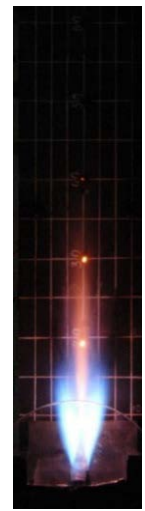

$a$

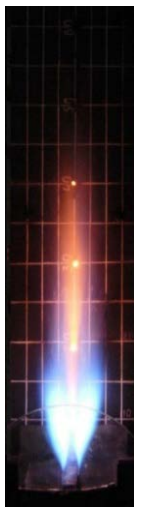

$b$

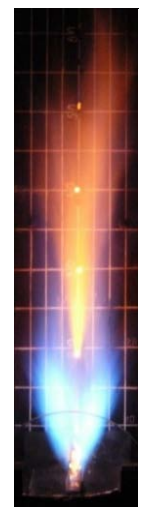

C

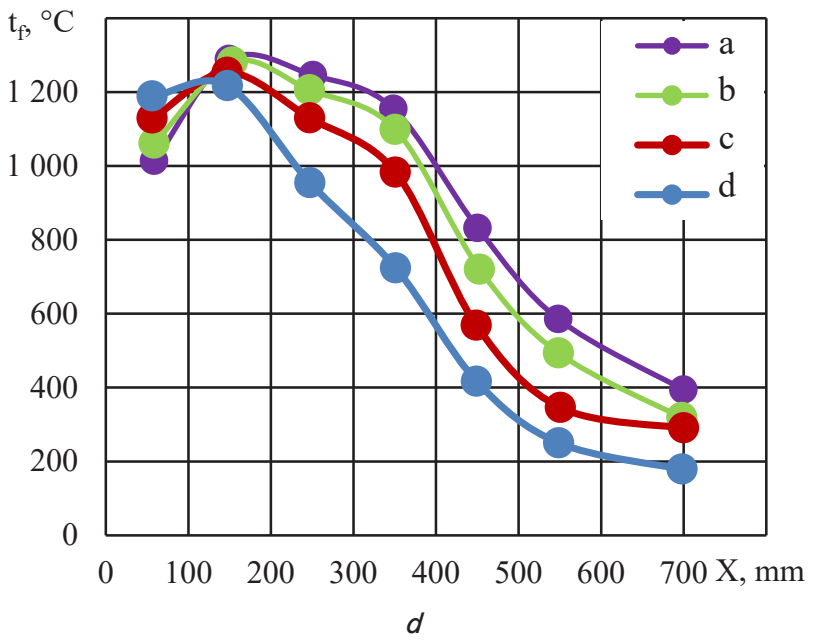

Fig. 21. Characteristics of fuel combustion (propane-butane) after the stabilizer with gas supply to the streamline airflow according to scheme I from the holes at the edges of stabilizer 15.5-0.155-14Ø3-15-I; $W_{c}=6,6 \mathrm{~m} / \mathrm{s}$;

$a-d-$ photographs of the torch; $e-$ the temperature of gases along the axis of the trace after the stabilizer; modes: $a-G_{g}^{\mathrm{I}}=0.44 \cdot 10^{-3} \mathrm{~kg} / \mathrm{s} ; \quad b-G_{g}^{\mathrm{I}}=0.62 \cdot 10^{-3} \mathrm{~kg} / \mathrm{s} ;$ $c-G_{g}^{\mathrm{I}}=0.90 \cdot 10^{-3} \mathrm{~kg} / \mathrm{s} ; \quad d-G_{g}^{\mathrm{I}}=1.1 \cdot 10^{-3} \mathrm{~kg} / \mathrm{s}$

\section{at} the level of breaking edges of stabilizer 15.5-0.155-14Ø3-15-I $\left(L_{1}^{\mathrm{I}}=15 \mathrm{~mm}\right)$ :

- case; 2-4 - nozzle, leveling chamber, and gas supply holes at the stabilizer 
Fig. 21, $d$ shows that the maximum temperature of the torch exceeds $1,200{ }^{\circ} \mathrm{C}$, which is enough to reliably provide ballasted fuel. With an increase in gas consumption, the length of the torch increases accordingly, which indicates the diffusion of the combustion process; at the same time, the maximum temperature of gases also increases. It is noteworthy that, in this case, the expansion of the torch begins already at the cut of the stabilizer.

When analyzing temperature field data, it can also be noted that the process of burning the bulk of the fuel occurs at the initial section of the torch.

As an example of burner device operation with combined gas distribution, Fig. 22 shows the evolution of fuel combustion after the stabilizer with the supply of ballasted gas according to scheme II (15.5-0.155-16Ø3-85-II), and the next gas - according to scheme I from the holes, placed closer to the edges of the stabilizer (15.5-0.155-14Ø3-15-I). Table 2 gives the test modes.

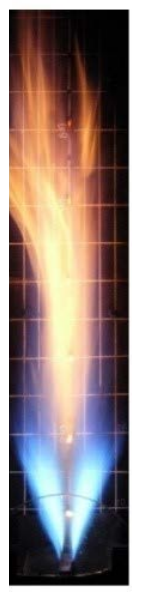

$a$

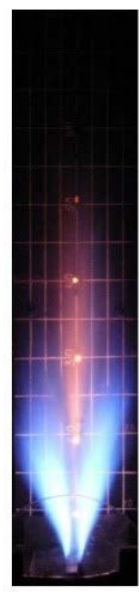

$b$

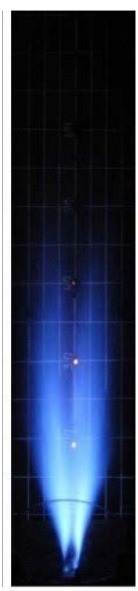

c

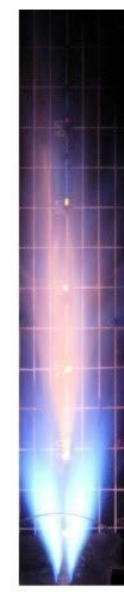

$d$

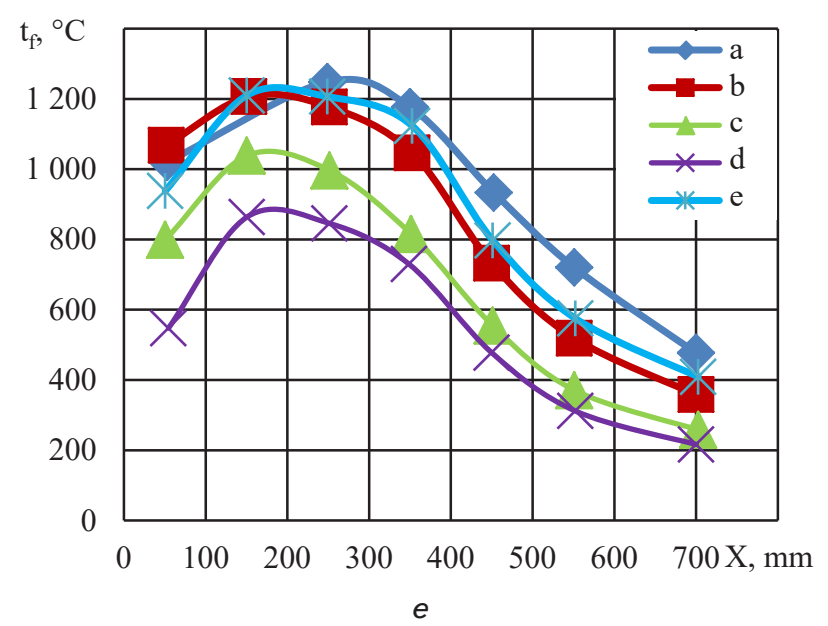

Fig. 22. Evolution of fuel combustion after the stabilizer during combined operation; $W_{c}=6,8 \mathrm{~m} / \mathrm{s}$;

$a-e-$ photographs of the torch during combined work with the supply of the main gas and carbon dioxide according to scheme II (15.5-0.155-16Ø3-85-I)

and additional supply of stabilizing gas according to scheme I from the holes closer to the edges of the stabilizer (15.5-0.155-14Ø3-15-I);

$f-$ the temperature of combustion products under different modes of operation
Table 2

Stabilizer test modes for combined gas supply according to scheme I and scheme II involving the pre-mixing with carbon dioxide

\begin{tabular}{|c|c|c|c|c|c|}
\hline Mode & $a$ & $b$ & $c$ & $d$ & $e$ \\
\hline$G_{g}^{\mathrm{II}} \cdot 10^{-3}, \mathrm{~kg} / \mathrm{s}$ & 1.4 & 1.4 & 1.4 & 1.4 & 1.4 \\
\hline$G_{\mathrm{CO}_{2}}^{\mathrm{I}} \cdot 10^{3}, \mathrm{~kg} / \mathrm{s}$ & - & 1.9 & 2.5 & 2.85 & 2.85 \\
\hline$G_{g}^{\mathrm{I}} \cdot 10^{-3}, \mathrm{~kg} / \mathrm{s}$ & - & - & - & - & 0.31 \\
\hline
\end{tabular}

When feeding, for premixing, carbon dioxide with gas, the torch length decreases, as can be seen from the modes $a-c$. When enabling the supply of additional regular gas from the holes, placed closer to the edges of the stabilizer, the torch length increases, and the temperature of the gases rises (mode $e$ ).

When arranging fuel feed holes, it should be borne in mind that the holes for supplying additional regular fuel should be shifted half a step in relation to the main fuel supply holes. According to this scheme, jets of main fuel with impurities pass into the combustion zone between the high-temperature jets of additional fuel.

The ANSYS Fluent (USA) software suite was employed [31] to analyze the jet fuel flow (propane-butane) when exiting the gas holes located on the side walls of the stabilizer. Fig. 23 shows estimation data on the pattern of fuel concentration that emanates from two systems of gas holes located at distance $L_{1}=85 \mathrm{~mm}$ and $L=15 \mathrm{~mm}$ from the breaking edge of the stabilizer.
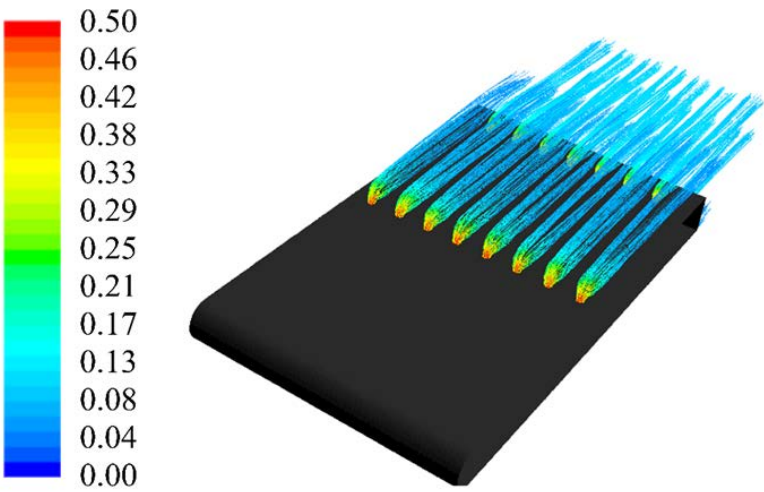

Fig. 23. Fields of the evolution of concentrations of gas jets emanating from the systems of holes for stabilizer 15.5-0.155-16Ø3-85-II and 15.5-0.155-14Ø3-15-I, $W_{\mathrm{a}}=10 \mathrm{~m} / \mathrm{s} ; W_{\mathrm{g}}=10 \mathrm{~m} / \mathrm{s}, t_{\mathrm{g}} / d_{\mathrm{g}}=3,5$

As can be seen from the change in the color of lines corresponding to the concentration of gas, the maximum degree of mixing is observed at the exit points of the jets, after the fuel jet moves concomitantly to the airflow, and the difference in the speed of the reagents decreases, the intensity of mass exchange decreases.

Fig. 24 shows the view of the field of fuel concentrations from the end of the stabilizer (on its cut).

The field of concentrations demonstrates that in order to ensure the effective operation of the burner device, the jets of additional fuel must be located between the jets of the main fuel. The distance between the rows of supply of ballasted and highly-reactive fuels must be chosen provided that a high-quality mixture of both fuels is formed with air without the fusion of torches. 

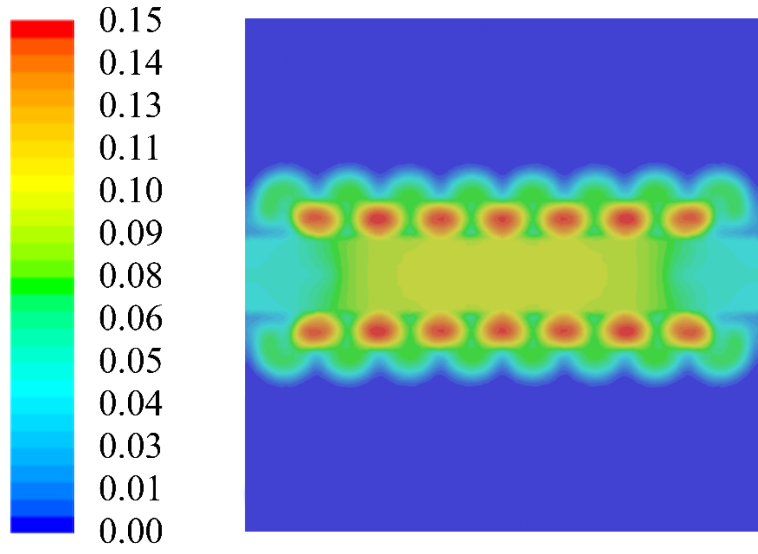

Fig. 24. View of the field of fuel concentrations (propanebutane) towards the flow at the level of the end cut of the stabilizer

\section{Discussion of results of testing a stabilizer burner device when combusting ballasted gases}

Our study result has shown the possibility of burning in stabilizing burner devices of ballasted gas fuels of variable composition. The limits of stable combustion of fuel for lean torch detachment in stabilizer burners under different fuel supply schemes have been established, depending on the mode and design parameters of the system. When supplying fuel according to scheme I - Fig. 16 (5). When supplying fuel according to scheme II - Fig. 7 (1). The limits of the stable operation of the burner have been established when the concentration of ballast impurities in fuel is changed - Fig. 8, (2) to (4). The possibility of expanding the boundaries of stable combustion of ballasted fuel by simultaneously supplying ballasted and highly-reactive fuel to the combustion zone according to combined schemes has been shown - Fig. 18, 19, 22.

Through the use of combined schemes, the possibilities of using various types of fuels are expanded, including ballasted low-reactive, in the energy and industry, thereby promoting the replacement of costly methane and improving environmental protection. Unlike the schemes and designs of burner devices and combustion chambers in $[6,8]$, stabilizer burners have a series of advantages. They include the modularity of the structure and the possibility of influencing the air pressure loss in the burner by changing the shading coefficient of the stabilizer grid. Combustion stability indicators can be adjusted by changing the design parameters of the burner, for example, the width of the stabilizer, the shading coefficient, the airspeed. In addition, due to the adopted principle of organizing the workflow in stabilizer burners, there is no possibility of flame slipping into the burner.

The limitations inherent in this paper are that the studies were carried out at small shading coefficients of the stabilizer lattice $K_{f}<0.5$, which currently limits the scope of use of the study results. The influence of such a factor as airflow turbulence has not been investigated. At this stage of research, the effect exerted on the characteristics of the burner by the relative distance between the gas holes when supplying both fuels, highly- and low-reactive, to streamline airflow, has not been shown.

Our study can be advanced by testing the stabilizer system in a closed bench involving the measurement of all the necessary parameters of the working body, as well as the widespread use of computer simulation methods.

\section{Conclusions}

1. We have defined and derived generalized formulas on the influence of structural and regime factors on the characteristics of the stability of torch burning after the stabilizer exerted by lean detachment when supplying highly reactive fuel (propane-butane) according to two schemes. According to the diffuse scheme I, fuel was fed in the recirculation zone after the stabilizer. According to scheme II, fuel by jets was supplied for preliminary mixing into a streamlined airflow. The coefficient of excess air under the mode of lean detachment when supplying gas to the recirculation zone is greater than when supplying to the streamline airflow. If it is necessary to increase the stability of the torch in both cases, it is necessary to increase the width of the stabilizer and reduce the airspeed at the initial edge of the stabilizer.

2. When supplying fuel according to scheme II and increasing the content of ballast in fuel (air, carbon dioxide), there is a gradual decrease in the length of the torch, a decrease in the maximum combustion temperature. At a critical ballast content in fuel, the result of a decrease in heat generation in the torch is the burning detachment. The general dependence of torch stability on ballast content has been established. At a ratio of ballast consumption to fuel gas within 2.0, the release of nitrogen oxides is reduced by 6 times.

3. We have built a method for increasing the stability of combustion of ballasted fuel at the concentration of impurities from $0 \%$ to $100 \%$ (lack of fuel). To this end, the combined fuel supply is adopted - low-reactive according to scheme II, into the streamline airflow, and highly-reactive fuel - according to scheme I, in the recirculation zone after the stabilizer. In this scheme, the jets of ballasted fuel pass through highly temperature diffusion torches, and the combustion process of both fuels occurs regardless of the concentration of impurities in the ballasted fuel. The power of the burner is maintained by increasing the fuel consumption supplied to the next torch with the preservation of the thermal power of the burner. The stability and length of the general torch are determined by the characteristics of the diffusion torch. In the case of supplying all gas according to a first scheme, with an increase in fuel consumption, the main mass of gas leaves the recirculation zone; a detachment of the torch from the stabilizer is likely - "rich" detachment. Therefore, when supplying fuel according to scheme I, it is possible to ensure the constant operation of the burner at an air excess $\alpha>1.0$.

4. For the operation of the burner device with an excess air coefficient exceeding unity or approaching unity, ballasted fuel is recommended to feed by immersion in a streamlined airflow from the holes on the side walls of the stabilizer. Highly reactive fuel is also supplied from the holes placed on the side walls of the stabilizer down the airflow behind the low-reactive fuel supply holes. Calculations of gas distribution systems are carried out according to relevant procedures. In this case, jets of ballasted fuel pass between the jets of highly reactive fuel. 
References

1. Klumchuk, O. V., Grokh, N. V. (2012). Production of biogas: experience of foreign countries and prospect of development is in Ukraine. Zb. Naukovykh prats VNAU, 2 (64), 50-54. Available at: http://econjournal.vsau.org/files/pdfa/869.pdf

2. Kholod, N., Evans, M., Pilcher, R. C., Roshchanka, V., Ruiz, F., Coté, M., Collings, R. (2020). Global methane emissions from coal mining to continue growing even with declining coal production. Journal of Cleaner Production, 256, 120489. doi: http:// doi.org/10.1016/j.jclepro.2020.120489

3. Vladimirov, Ia. A., Zysin, L. V. (2018). Methodological aspects of energy utilization of municipal solid waste and its gasification products. Nauchno-tekhnicheskie vedomosti SPbPU. Estestvennye i inzhenernye nauki, 24 (1), 5-16. Available at: doi: http:// doi.org/10.18721/JEST.240101

4. Liu, C., Yan, B., Chen, G., Bai, X. S. (2010). Structures and burning velocity of biomass derived gas flames. International Journal of Hydrogen Energy, 35 (2), 542-555. doi: http://doi.org/10.1016/j.ijhydene.2009.11.020

5. Sigal, I. Ia., Marasin, A. V., Smikhula, A. V., Sigal, A. I., Kolchev, V. A. (2013). Experimental study of biogas burning and it use in industrial boilers. International Scientific Journal for Alternative Energy and Ecology, 17 (139), 84-89. Available at: https://cyberleninka.ru/article/n/eksperimentalnoe-issledovanie-goreniya-biogaza-i-ego-ispolzovanie-v-promyshlennyh-kotlah/viewer

6. Sigal, I. Ia., Smikhula, A. V., Marasin, A. V., Kuts, V. P., Dombrovskaia, E. P., Kolchev, V. A., Kernazhitskaia, E. S. (2013). Experimental Research of a Biogasas a Fuel for Boilers. Energotekhnologii i resursosberezhenie, 5, 26-32. Available at: http://dspace.nbuv.gov. ua/handle/123456789/127237?show=full

7. Anggono, W., Wardana, I. N. G., Lawes, M., Hughes, K. J., Wahyudi, S., Hamidi, N., Hayakawa, A. (2013). Biogas Laminar Burning Velocity and Flammability Characteristics in Spark Ignited Premix Combustion. Journal of Physics: Conference Series, $423,012015$. doi: http://doi.org/10.1088/1742-6596/423/1/012015

8. Hosseini, S. E., Bagheri, G., Khaleghi, M., Abdul Wahid, M. (2015). Combustion of Biogas Released from Palm Oil Mill Effluent and the Effects of Hydrogen Enrichment on the Characteristics of the Biogas Flame. Journal of Combustion, 2015, 1-12. doi: http:// doi.org/10.1155/2015/612341

9. Sigal, I. Ia., Marasin, F. V., Smikhula, A. V. (2014). Gas Burners for Combustion of Biogas in Boilers. Energotekhnologii i resursosberezhenie, 3, 68-72. Available at: http://dspace.nbuv.gov.ua/handle/123456789/127295

10. Komina, G. P. (2018). Environmental characteristics of combustion of gasesin a closed ring flame. Voda i ekologiia: problemy i resheniia, 1 (73), 39-47.

11. Koliienko, V. A., Halinska, T. A., Shelimanova, O. V. (2015). Combined burning of mixture of natural and producer gases. Naukovyi visnyk NUBiP Ukrainy, 5, 136-138. Available at: http://nbuv.gov.ua/UJRN/nvnau_tech_2015_224_26

12. Slavinskaia, N. A. (2007). Proekt Evropeiskogo soiuza «Vysokoeffektivnaia gazovaia turbina s primeneniem sinteticheskogo gaza». Gazoturbinnye tekhnologii, 24-27.

13. Lebedev, A. S., Simin, N. O., Tarasov, D. S., IUshkevich, A. V. (2010). Rabota kamer sgoraniia GTU na produktakh gazifikatsii tverdogo topliva. Teploenergetika, 6, 73-79.

14. Serbyn, S. Y., Honcharova, N. A., Vylkul, V. V. (2015). Studying the peculiarities of the working process in the combustion chamber of synthetic gas-operated turbine engine of 2.5MW. Visnyk NTU «KhPI», 16 (1125), 14-18. Available at: http://repository.kpi. kharkov.ua/handle/KhPI-Press/17564

15. Escudero, M., Jiménez, Á., González, C., Nieto, R., López, I. (2012). Analysis of the behaviour of biofuel-fired gas turbine power plants. Thermal Science, 16 (3), 849-864. doi: http://doi.org/10.2298/tsci120216131e

16. Gómez, M., Amell, A., Zapata, L. (2015). Spark ignition engine performance and emissions in a high compression engine using biogas and methane mixtures without knock occurrence. Thermal Science, 19 (6), 1919-1930. doi: http://doi.org/10.2298/tsci140829119g

17. Rowhani, A., Tabejamaat, S. (2015). Experimental study of the effects of swirl and air dilution on biogas non-premixed flame stability. Thermal Science, 19 (6), 2161-2169. doi: http://doi.org/10.2298/tsci130112157r

18. Butovskii, L. S., Granovskaia, E. A., Fialko, N. M. (2010). Ustoichivost fakela za ploskim stabilizatorom pri podache gaza vnedreniem v vozdushnii potok. Tekhnologicheskie sistemy, 3 (52), 72-76. Available at: http://technological-systems.net/index.php/ Home/article/view/455

19. Butovskii, L. S., Granovskaia, E. A., Fialko, N. M., Strokin, V. N., Shvetsova, L. A. (2011). Povyshenie ustoichivosti fakela pri podache gaza v zonu retsirkuliatsii za stabilizatorom. Tekhnologicheskie sistemy, 3 (56), 74-81.

20. Jet- derived low-NOx combustors to be offered for Land-based mashines (1990). Gas Turbine World, 20 (6), 30.

21. Keppel, W. (1994). 20 jahre ABB - gasturbinen typ 13: von 55 bis $165 \mathrm{MWt}$ - spiegelbild einer evolution. VGB Kraftwerkstechnik, 74, Heft 4, 361-372.

22. Funke, H. H.-W., Keinz, J., Kusterer, K., Ayed, A. H., Kazari, M., Kitajima, J. et. al. (2017). Development and Testing of a Low NOx Micromix Combustion Chamber for Industrial Gas Turbines. International Journal of Gas Turbine, Propulsion and Power Systems, 9 (1), 27-36. doi: http://doi.org/10.38036/jgpp.9.1_27

23. Sudarev, A. V., Butovsky, L. S., Granovskya, E. A. (1994). Process studies applied to ceramic gas turbine engine low-emission double-zone micro-diffusion combustion chamber. ASME Paper, 94-GT-445. Hagus, 6. doi: http://doi.org/10.1115/94-gt-445 
24. Gadde, S., Wu, J., Gulati, A., McQuiggan, G., Koestlin, B., Prade, B. (2006). Syngas capable combustion systems development for advanced Gas turbines. ASME TURBO EXPO 2006. Paper GT 2006-90970. Barcelona. doi: http://doi.org/10.1115/gt2006-90970

25. Lefebvre, A. H., Ibrahim, A. R. A. F., Benson, N. C. (1966). Factors affecting fresh mixture entrainment in bluff-body stabilized flames. Combustion and Flame, 10 (3), 231-239. doi: http://doi.org/10.1016/0010-2180(66)90079-4

26. Chigier, N. A., Mech, A. M. I., Gilbert, J. L. (1968). Recirculation Eddies in the Wake of Flameholders. Journal of the Institute of Fuel, 3, 105-112.

27. Winterfeld, G. (1965). On processes of turbulent exchange behind flame holders. Symposium (International) on Combustion, 10 (1), 1265-1275. doi: http://doi.org/10.1016/s0082-0784(65)80261-2

28. Abdulin, M. Z., Siryi, A., Tkachenko, O. M., Kunyk, A. A. (2020). Boilers modernization due to energy-ecological improvement technology of burning. Bulgarian Chemical Communications, 52, 14-19. Available at: http://www.bcc.bas.bg/bcc_volumes/Volume_52_Special_F_2020/BCC-52-F-2020-14-19-Abdulin-2.pdf

29. Raushenbakh, B. V., Belii, S. A., Bespalov, I. V. et. al. (1964). Fizicheskie osnovy rabochego protsessa v kamerakh sgoraniia vozdushno-reaktivnykh dvigatelei. Moscow: Mashinostroenie, 526.

30. Bauer, A. B. (1967). Some experiments in the near wake of cones. AIAA Journal, 5 (7), 1356-1358. doi: http:// doi.org/10.2514/3.4202

31. Ansys Fluent 14.0 Theory Guide from https://www.scribd.com/doc/140163341/Ansys-Fluent-14-0-Theory-Guide 